\title{
New Pharmacological Agents to Aid Smoking Cessation and Tobacco Harm Reduction: What has been Investigated and What is in the Pipeline?
}

\author{
Emma Beard ${ }^{1,2}$, Lion Shahab ${ }^{1}$, Damian M. Cummings ${ }^{3}$, Susan Michie ${ }^{2}$ \& Robert West ${ }^{1}$ \\ ${ }^{1}$ University College London, Department of Epidemiology and Public Health, London, UK \\ ${ }^{2}$ University College London, Department of Clinical, Educational and Health Psychology, London, UK \\ ${ }^{3}$ University college London, Department of Neuroscience, Physiology \& Pharmacology, London, UK
}

Running header: New Agents for smoking cessation and tobacco harm reduction

Word count: 12,739

Journal: Invited by CNS drugs

Correspondence: Emma Beard, Cancer Research UK Health Behaviour Research Centre, University College London, WC1E 6BP, UK. Email: e.beard@ucl.ac.uk. Tel: 02031083179 


\section{Abstract}

A wide range of support is available to help smokers to quit and aid attempts at harm reduction, including three first-line smoking cessation medications: nicotine replacement therapy, varenicline and bupropion. Despite the efficacy of these, there is a continual need to diversify the range of medications so that the needs of tobacco users are met. This paper compares the first-line smoking cessation medications to: 1) two variants of these existing products: new galenic formulations of varenicline and novel nicotine delivery devices; and 2) twenty-four alternative products: cytisine (novel outside of central and eastern Europe), nortriptyline, other tricyclic antidepressants, electronic cigarettes, clonidine (an anxiolytic), other anxiolytics (e.g. buspirone), selective 5-hydroxytryptamine (5-HT) reuptake inhibitors, supplements (e.g. St John's wort), silver acetate, nicobrevin, modafinil, venlafaxine, monoamine oxidase inhibitors (MAOI), opioid antagonist, nicotinic acetylcholine receptors (nAChR) antagonists, glucose tablets, selective cannabinoid type 1 receptor antagonists, nicotine vaccines, drugs that affect gamma-aminobutyric acid (GABA) transmission, drugs that affect $\mathrm{N}$-methyl-D-aspartate receptors (NMDA), dopamine agonists (e.g. levodopa), pioglitazone (Actos; OMS405), noradrenaline reuptake inhibitors, and the weight management drug lorcaserin. Six criteria are used: relative efficacy, relative safety, relative cost, relative use (overall impact of effective medication use), relative scope (ability to serve new groups of patients), and relative ease of use (ESCUSE). Many of these products are in the early stages of clinical trials, however, cytisine looks most promising in having established efficacy and safety and being of low cost. Electronic cigarettes have become very popular, appear to be efficacious and are safer than smoking, but issues of continued dependence and possible harms need to be considered.

\section{Key points:}

- This paper reviews 26 pharmacotherapies that have been investigated for tobacco harm reduction and smoking cessation alongside three first-line treatments (nicotine replacement therapy, varenicline and bupropion) on six criteria: relative efficacy, relative safety, relative cost, relative use, relative scope, and relative ease of use.

- Although many of these products are in the early stages of clinical trials, of all the medications considered, cytisine appears to offers the best prospect for the future, having established safety and efficacy and being very inexpensive. Electronic cigarettes have become very popular in some countries but efficacy and long-term safety compared with other treatment profiles require further consideration. 


\section{Introduction}

Despite significant declines in the prevalence of tobacco use in many countries over the past couple of decades [1], smoking remains the leading avoidable cause of premature death worldwide, accounting for more than 5 million deaths per year [2]. Smoking is also responsible for multiple morbidities including cancer, heart disease, stroke, emphysema, bronchitis, chronic airway obstruction, and diabetes [3].

Bupropion, nicotine replacement therapy (NRT), and varenicline are licensed as first-line smoking cessation aids in Australia, the European Union, and North America, and are recommended in many national guidelines [4]. There is substantial evidence from clinical trials, population studies, and routine clinic data for the efficacy of these medications for cessation, and the use of NRT for harm reduction [5-10].

Yet, some smokers find these three traditional medications unacceptable [11] and in many countries they are not affordable [12]. This paper aims to review alternative medications which have been assessed for smoking cessation and harm reduction alongside the three first-line products using six criteria that we propose (ESCUSE): relative efficacy, relative safety, relative cost, relative usse (overall impact of effective medication use), relative scope (ability to serve new groups of patients), and relative ease of use.

\subsection{ESCUSE criteria}

\subsubsection{Relative efficacy: Is the product more efficacious than existing drugs?}

Efficacy is the extent to which an intervention does more good than harm under ideal circumstances (usually a clinical trial) i.e. does the drug work? We are often interested in whether novel treatments have greater or similar efficacy to established pharmacotherapy. However, efficacy is often hard to address for novel treatments due to the absence of long-term clinical trials. Indeed, up to $97 \%$ of data on the efficacy of medication is based on short term surrogate end-points [13]; and even where high quality clinical data are available, medicines sometimes do not perform as expected in everyday clinical practice [14]. This is because effectiveness - the ability of a drug to produce a beneficial effect in real-world settings - is highly dependent on compliance with the drug routine. However, the effect of delivery in routine clinical settings is generally only possible to assess once a drug is licensed for its indication. Consequently, where information on efficacy and effectiveness are unavailable, we will draw conclusions from research on other drugs with similar pharmacotherapy profiles. For example, both cytisine and varenicline act as nicotinic receptor partial agonists, while NRT and electronic 
cigarettes are based on the principle of providing pure nicotine without the toxic constituents of tobacco.

\subsubsection{Relative safety: Is the product safer than existing drugs?}

The safety profile of a drug is often viewed as a top priority in evaluating the possible public health impact of a novel treatment. A product which is equally effective as an existing product, but deemed less dangerous, will likely have an overall public health benefit; while a product which is equally effective, but deemed more dangerous, may have a negative public health impact [15]. Side effects can range from being mild and short-lived to being severe and long-lasting, the latter needing to be minimised or ideally removed in products coming to market. Generally, evidence for the safety profile of a drug comes from clinical trials and population surveillance. However, as a number of novel treatments have not been evaluated long-term, safety assurances necessarily rely on expert judgment and pharmacological profiles, and should be updated regularly as new information emerges. For instance, research in the US shows that post-marketing surveillance generally only identifies serious drug reactions a median of three years after approval [16].

\subsubsection{Relative cost: Is the product cheaper than existing drugs?}

The cost of a new drug should always be considered in the overall assessment of its place in the treatment of dependence. Around the world, health-care service budgets are increasingly under strain, and thus drugs which are deemed effective may only be available if they come at a suitable cost. Indeed, cost-effectiveness is viewed as the 'fourth hurdle' among the criteria of drug regulation and licensing decisions, given that the cost of new drugs is nearly always significantly higher than the drugs they aim to replace [17].

1.1.4 Relative use: Will the product increase the number of patients using some form of effective medication?

Increased public health benefits at a population level from new treatments will occur either when: 1) smokers switch to a more effective novel product; or 2) the novel product entices smokers not using pharmacotherapy to use effective medication. Thus, there is a need to assess whether the presence of the drug in the market will increase the overall use of pharmacotherapy. Prior to the drug's availability, informed hypotheses can be made but it is not possible to ascertain its true impact. Even once the drug is in use at a population level, long-term surveillance will be required since initial effects may not be maintained [18]. 
1.1.5 Relative scope: Does the product serve groups of patients who are not adequately served by existing drugs?

Often the aim of novel treatments is to serve a group of patients who are not adequately served by existing medications. Medications regularly have contraindications for at-risk populations and are not equally available in all countries. For example, patients who are pregnant, suffer from cardiovascular disease, and/or have psychiatric conditions, are often warned against condition-unrelatedpharmacotherapy due to the possibility of adverse effects. Novel treatments can also be required to meet individual preferences for the delivery method, the potency and action of a drug $[11,19]$. There have been increasing moves towards the personalisation and stratification of treatment, including 'mutually agreed tailoring', which involves the management of conditions by incorporating specific needs and experiences with clinical judgement to decide on drug routines [20-23].

1.1.6 Relative ease: Is the product easier to take than existing drugs?

Less than half of all drugs are taken as recommended [24]. Consequently, simplifying a drug routine can be an important step in promoting adherence. Simplification can involve reducing dose complexity (e.g. from four times a day to once a day), changing the mode of delivery (e.g. from injection to tablet) and helping patients to integrate the regimen into their daily lives [24].

\section{First-line treatments for smoking cessation and harm reduction}

NRT was introduced in 1978 in Switzerland as a chewing gum formulation (Canada in 1979 and UK in 1980) followed by the nicotine patch in the US in 1992 [25]. The basis of the development of NRT was evidence that the main addictive component of cigarettes is nicotine [26-28], but that it is the other thousands of chemicals resulting from cigarette combustion that cause the excess mortality and morbidity $[29,30]$. The market over the next 30 years expanded rapidly, with the development of faster acting products such as the nicotine inhalator, nicotine lozenges, nicotine nasal spray, fast dissolving oral nicotine strip and nicotine mouth spray [31,32]. Variations also became available in a number of counties including high strength patches [33], rapid delivery gums [34] and mini lozenges which dissolve more quickly than the standard lozenge [35]. These products were initially only licensed for smoking cessation but have subsequently been recommended in a number of countries, including the UK, for harm reduction [36].

The next first-line treatment introduced to market was bupropion. This atypical antidepressant was proposed as a smoking cessation aid by Ferry in 1989 following the observation that smokers taking it for depression stopped smoking spontaneously [37]. However, it was not approved as a smoking cessation aid until 1997, after a series of manufacturer funded clinical trials [37]. Bupropion, marketed 
under its trade name Zyban and Wellbutrin, is thought to help smokers to quit through its ability to inhibit the neuronal reuptake of dopamine, noradrenaline (norepinephrine) and serotonin/5hydroxytryptamine (5-HT) [38].

The third first-line treatment varenicline (Chantix, Champix), a nicotinic acetylcholine receptor (nAChR) partial agonist and synthetic derivative of the alkaloid cytisine, entered the UK and US markets in 2006 [39, 40]. It was hypothesised that a partial agonist of nAChRs would lead to a moderate and sustained increase of mesolimbic dopamine levels, thus reducing withdrawal symptoms. At the same time, varenicline was argued to shield a smoker from dependence-maintaining increases in neurotransmitters due to its higher affinity to nAChRs than the native ligand, nicotine, and therefore reduce the rewarding effects of smoked tobacco [41].

Table 1 applies the ESCUSE criteria to these three first-line treatments and forms the baseline for comparing novel pharmacotherapies. Varenicline appears to be the most effective of the three medications, but has the greatest number of apparent side effects and contraindications. NRT offers smokers greater variety and is substantially cheaper but often is not adhered to or used correctly, while bupropion may be a suitable treatment for individuals with co-morbid depression diagnoses but is also associated with increased seizure risk.

\section{Other pharmacotherapy for smoking cessation and harm reduction}

Over the past couple of decades attempts have been made to devise alternative novel pharmacotherapies based either on the first-line treatments or drugs which work via alternative mechanisms. These products are reviewed below, starting with variants of existing products and then products with novel mechanisms, in order of their likely efficacy.

\subsection{Variants of Existing Products}

\subsubsection{Novel nicotine delivery products}

Promoted by the unpleasant taste and side effects of traditional NRT products $[42,43]$, a number of alternative devices have been proposed. These included the nicotine straw, a single use straw which contains small beads and drops of nicotine [44]; nicotine pouches, which contain flavoured nicotine granules [45]; pulmonary nicotine delivery devices, which deliver nicotine into the lungs in the form of nebulisers, pressurised metered-dose inhalers and other non-metered-dose inhalers [46]; carbon nanotubes which are transdermal and have gate-keeping properties [47]; the Nicotine Cannon, a widebore nicotine delivery device which holds up to five inhalator cartridges [48]; and other nicotine films which attempt to combine the properties of both oral and transdermal products i.e. increased speed of nicotine delivery, flexibility in application and bi-phasic nicotine release [49]. Most remain in early 
stages of development, with the exception of the nicotine pouch which is available in some countries, including Sweden, while work on the nicotine straw has become dormant for unknown reasons [32].

\section{Relative efficacy}

Although there is currently limited evidence for the efficacy of these novel nicotine delivery devices in relation to smoking cessation, preliminary data suggests that they may be as effective as or more effective than licensed NRT in reducing withdrawal symptoms and desire for cigarettes [32]. Some of the products deliver nicotine as fast or faster than licensed NRT and are judged to be more enjoyable and satisfying to use. In a repeated measures crossover trial the nicotine cannon alleviated urges to smoke and was deemed to be more acceptable by users, while a small randomised trial of twenty-four smokers found that plasma levels of nicotine peaked between 1 and $2 \mathrm{hr}$ after a single dose, which is comparable with that of other nicotine replacement products $[44,50]$. However, the nicotine straw is likely to be ineffective when used in combination with beverages with lower pH values [43]. Nebulisers and nicotinic inhalers have also been shown to reduce the desire for cigarettes [46, 51]. Carbon nanotubes through their ability to control flow of nicotine across the membrane may over-come many of the limitations of the traditional patches, allowing programmable variable drug delivery rates [52].

\section{Relative safety}

Devices that deliver nicotine through the bronchial alveoli, as is achieved by cigarettes, may have greater abuse potential [44]. Although many of the products, including the nicotine straw, are well tolerated [53]; they have mild side effects, particularly the pulmonary delivery devices which are aversive at high doses [50]. A recent systematic review reported that nebulizers elicit dose-dependent coughs [54]. Dose-dependent reflux interruption of smooth inspiration has also been reported for metered-dose inhalers in clinical trials [54]. However, some novel products may have more favourable side effects than established NRT, which can cause hiccups, nausea and local irritation.

\section{Relative cost}

Although adaptations of an existing product has the advantage of being potentially cheaper and easier to produce and license than the other treatments discussed below, some of these products may be more expensive (e.g. the nicotine cannon which requires multiple inhalator cartridges) [41].

\section{Relative use}

None of the products, with the exception of nicotine pouches, are currently available to smokers. However, if they were to be licensed it is likely that they will increase overall use of non-tobacco nicotine containing products, based on evidence that bringing new nicotine delivery devices into the 
market results in more smokers trying pharmacological aids [55]. Previous studies suggest that novel products do not simply substitute for existing ones $[56,57]$.

\section{Relative scope}

These products may be particularly suitable for those who find traditional NRT products ineffective or unacceptable [58]. However, they are likely to be contraindicated for similar populations as traditional NRT products and may, in the case of pulmonary delivery devices, have a greater number of side effects.

\section{Relative ease of use}

Use of these nicotine delivery devices is similar to traditional NRT products. For example, the nicotine cannon 50mg (5 x 10mg cartridges) and pulmonary delivery devices can be used as needed, while nicotine straws in 4, 8 or $12 \mathrm{mg}$ can be used every 1-2 hours.

\subsubsection{New galenic formulations of varenicline}

Galenic formulations of varenicline have been considered in order to improve the efficacy and acceptability of the traditional varenicline formulation. Galenic formulation is the process of medication preparation and compounding in order to optimise both the rate and extent of medication absorption. To date three new galenic formulations of varenicline have been proposed and are currently being tested in randomised controlled trials.

The first is a free base patch which aims to deliver varenicline transdermally. Four phase 1 clinical trials assessing absorption rates and tolerability have been completed (Clinical trial identifier and completion date: NCT01234142 in 2011 and NCT01013454 in 2009, NCT00661765 in 2009 and NCT00774605 in 2009).

The second is a controlled-release tablet formulation. This aims to slow the rate of release of varenicline in the gastro-intestinal tract and extend the absorption phase [59]. This has been achieved using an osmotic controlled-release system, where a tablet core made from varenicline, mannitol, microcrystalline cellulose, and dicalcium phosphate, and is coated with a porous and semipermeable coating. As water enters the coating and the core, the drug is dissolved and released into the blood stream [60]. Two clinical trials have been completed which assessed the absorption rate, pharmacokinetics, safety and tolerability of single dose and escalating multiple oral doses of varenicline controlled-release tablets (NCT00731562 in 2010 and NCT00527150 in 2010). A further clinical trial, which planned to evaluate the safety and efficacy of three doses of controlled-release 
varenicline specifically for smoking cessation, was terminated prior to participant enrolment (NCT00741884).

The third is a free base solution which can be applied to the skin in the form of an ointment, cream or lotion. A spray form has also been proposed which would result in a more concentrated amount of the active ingredient on the skin due to evaporation. The sprayable liquid, in addition to varenicline, comprises a phospholipidic gel-forming agent, ethanol, phosphate buffer and distilled water [61]. A clinical trial assessing the absorption of varenicline into the body from a varenicline solution has been completed (NCT00774605 in 2009).

\section{Relative efficacy}

Results from the clinical trials have yet to be released; however, these novel formulations are likely to be as, if not more, efficacious than traditional formulations [41]. Slow release drug formulations often lead to better compliance and maintenance of plasma levels of the drug in therapeutic ranges [62]. The free-based patch form of varenicline will have the advantage of administrating a steady infusion of the drug over an extended period of time and adverse effects or therapeutic failure, which are often associated with intermittent dosing, will be avoided [63]. Free base varenicline solution have been shown to reduce nicotine administration in rats dose-dependently [64].

\section{Relative safety}

The reduced rate of passage and absorption of the controlled-release tablet formulation aims to reduce side effects associated with varenicline such as nausea [59]. Previous studies have shown that controlled-release bupropion reduces incidences of side-effects leading to treatment discontinuation [65]. There is also evidence to suggest that controlled-release medications are less likely to be abused or misused [62]. Free-base patches have an even better safety profile, in that drug input can be terminated at any point by removing the patch. However, they may lead to other side effects including skin irritation [63].

\section{Relative cost}

New galenic formulations are likely to be similar in price to traditional formulations of varenicline [66], which currently costs around $£ 164$ (US\$240) for 12 weeks [67].

\section{Relative use}

The introduction of traditional formulations of varenicline in the US resulted in a net increase in use of stop-smoking medications [68, 69]. However, since speculation of an association between varenicline and cardiovascular disease and suicidal idealisation, prescription rates have fallen [70-72]. 
Unless such concerns are reduced, new galenic formulations may not have a dramatic impact on overall effective mediation use.

Relative scope

New galenic formulations may be suitable for those patients who have failed with other medications but experience side effects with the traditional formulations of varenicline.

Relative ease of use

Controlled-release varenicline is in oral drug form which has the notable advantage of easy administration and free-based patches may improve compliance by simplifying the medical routine [63].

\subsection{Alternative Products: efficacy or likely efficacy}

\subsubsection{Cytisine}

Cytisine (marketed as Tabex) is a plant-based alkaloid found in members of the Leguminosae family. Like varenicline, it acts as a partial agonist of nAChRs and has a half-life of around 4.8 hours [73]. However, it would be wrong to suggest that this is a novel product worldwide. In fact, cytisine was developed as a treatment for tobacco dependence in Bulgaria in the early 1960s, and is still commercially available in Central and Eastern Europe.

\section{Relative efficacy}

Cytisine's initial distribution was restricted by early studies showing that it had poor absorption rates and limited effects on the brain [74, 75]. However, the 2006 positive review by Etter et al [76] and licensing of varenicline, which has a similar mechanism of action, brought renewed attention. Since then a number of studies have demonstrated its efficacy. A pragmatic, open-label, non-inferiority trial with 1310 adult daily smokers, noted that when combined with behavioural support, cytisine promotes continuous abstinence at 6 months to a greater extent than NRT; while a Cochrane systematic review reported that cytisine was four times more effective than placebo $[77,78]$.

\section{Relative safety}

Cytisine appears to have a greater number of side-effects than NRT, including gastro-intestinal problems [79], headaches, irritability, nausea, constipation and tachycardia [76]. Cytisine is also contraindicated for people with arterial hypertension and advanced atherosclerosis [76].

Relative use 
Cytisine is more cost-effective than currently licensed products, and so may be pivotal in helping to reduce social-inequalities in smoking cessation [80]. The cost of a course of cytisine is generally about 10 to $20 \%$ that of varenicline (US\$12 for full treatment) [80]. However, its development is hindered by the substantial investment that would be required to meet licensing requirements, and as a result, its advantage of being low cost may be lost in the process [81].

\section{Relative scope}

Given evidence that decreasing the price of treatments increases overall use of medication for smoking cessation [82], its presence in the world-wide market may increase overall use of effective medications. Evidence suggests a higher prevalence of smoking cessation aid use in Eastern Europe where cytisine is licensed as a smoking cessation aid relative to Southern Europe [83].

\section{Relative scope}

Due to its low cost, cytisine is likely to be beneficial for patients in developing countries and to be beneficial for those contraindicated for other medications. Indeed, combined use of nicotinic partial agonists and NRT is well tolerated [84]. It is derived naturally from the seeds of the plant Cytisus laborinum, which may be an important characteristic for smokers who do not wish to use a synthesised drug.

\section{Relative ease of use}

The most common dosing is $2-61.5 \mathrm{mg}$ tablets per day, which is greater than the oral dosing for varenicline but lower than the recommended dosing for non-transdermal nicotine products. For those patients who do not like oral administration, cytisine is also available as a film which is placed between the gum and lip and dissolves over time [76].

\subsubsection{Nortriptyline}

There was a rapid expansion of research into other antidepressants for smoking cessation following the advent of bupropion, with nortriptyline becoming a popular second-line treatment in many countries [85]. Nortriptyline is a tricyclic antidepressant, named after its chemical structure which contains three rings of atoms.

\section{Relative efficacy}

Nortriptyline has similar efficacy to both bupropion and licensed NRT [86]. Six-placebo controlled trials have shown that nortriptyline doubles quit rates [87]. A recent pragmatic randomised controlled trial of 901 smokers reported that prolonged abstinence at six months was $34 \%$ more likely among those 
receiving nortriptyline plus NRT relative to placebo plus NRT [88]. In this trial, nortriptyline was also found to reduced depression and anxiety but urges to smoke did not differ between groups.

Relative safety

Nortriptyline is believed to have similar effects on dopaminergic and adrenergic systems as bupropion, but tends to have greater side effects. These include dry mouth, urinary retention, constipation, sexual difficulties and seizure risk [87]. When used in combination with NRT excessive sweating and feeling shaky have been reported [88]. Concerns have been raised regarding the use of tricyclics for treatment of depression because of concerns about toxicity in overdose.

\section{Relative cost}

Nortriptyline is proposed to be much cheaper than bupropion. For example, in the Netherlands one month of treatment with bupropion costs around $€ 71.48$ (US\$ 81) compared with $€ 12.22$ (US\$ 14) for nortriptyline [89]. Nortriptyline also appears to have equivalent cost-effectiveness, supporting its utility [90].

Relative use

Nortriptyline has become a popular second-line treatment for smoking cessation in many countries, including New Zealand [91].

\section{Relative scope}

As with bupropion, Nortriptyline is likely to be particularly useful for those suffering from depression. However, it is contraindicated in those who have experienced myocardial infarction, have arrhythmias or severe liver disease. Thus, the medication is generally only used for those who fail with, have an adverse event in response to, or have a contraindication for, one of the first-line medications [19]. Many smokers may also be adverse to using a drug associated with treating psychiatric conditions.

\section{Relative ease of use}

Nortriptyline has a similar dosing profile to varenicline and bupropion: one oral tablet of 25 to $100 \mathrm{mg}$ per day or titrated dosages to serum levels recommended for depression.

\subsubsection{Electronic cigarettes}

Electronic cigarettes (e-cigarettes) are battery powered devices consisting of a cartomizer usually containing a mixture of nicotine, water, flavourings and propylene glycol or glycerine which produces a nicotine aerosol. Since e-cigarettes were first introduced into the market in 2003 , there have been 
significant developments to make them more efficient and appealing [92]. Regulation of e-cigarettes varies widely from country to country. Many countries have banned them (e.g. Brazil, Canada, Seychelles, Uruguay, Norway and Singapore), others have imposed heavy restrictions; and some have licensed them as medicines $[93,94]$ (e.g. in the UK: e-Voke produced by British American Tobacco [95]).

\section{Relative efficacy}

Only two RCTs have assessed e-cigarette use for smoking cessation, with a combined sample size of 662 participants. In both trials, early generation devices with low levels of nicotine were used. Pooled data from these two RCTs showed that use of nicotine-containing e-cigarettes was associated with higher abstinence rates relative to placebo, comparable abstinence rates to NRT, and a greater chance of reporting reductions in cigarette consumption of over $50 \%$ [96]. Although further trials are needed [96], similar efficacy has been noted in survey based studies [96-100].

\section{Relative safety}

There is no doubt that e-cigarettes are substantially less harmful than cigarettes since they do not contain tobacco, which when lit produces over 3,000-4,000 chemicals, many of which are carcinogenic [101]. Studies have identified a number of toxic chemicals in e-cigarette liquid (tobacco specific nitrosamines and diethylene glycol [102]; amino-tandalafil and rimonambant [103]; carbonyls (formaldehyde, acetaldehyde and acrolein) [104]; heavy metals (nickel, lead and cadmium) [104]; silicate particles [105]). However, the general consensus is that levels are low, unlikely to do harm, are substantially lower than those found in cigarettes; and in some cases, are similar to those found in NRT (e.g. nitrosamines) [106-108]. Nonetheless, continuous monitoring is warranted given the everchanging product landscape.

\section{Relative cost}

A single disposable e-cigarette costs around f6 (US\$ 9). Newer generation starter kits cost anything from $f 17$ to $f 90$ (US\$ 25 to 130), with a refill costing between $f 2$ (US\$3) and $f 4$ (US\$ 6) [109], which is less than or as expensive as purchasing NRT [110]

\section{Relative use}

The presence of e-cigarettes in the UK market appears to have increased the number of smokers using non-tobacco nicotine containing products [56]. Thus, it is likely that e-cigarettes are enticing new smokers to use smoking cessation aids rather than monopolising the current medications market. 
E-cigarettes are likely to be attractive for those smokers who miss the sensory and behavioural aspects of smoking. Currently available medicinal products, with the exception perhaps of some nontransdermal NRT, do not provide a similar sensation to smoking. E-cigarettes may be particularly suitable for those who have failed with other smoking cessation aids or for those whom these aids are contraindicated.

\section{Relative ease of use}

E-cigarettes provide the sensory and behavioural aspects commonly associated with smoking, i.e. the hand-to-mouth action. Smokers therefore often report they are more satisfying than NRT and so adherence is likely to be greater [111]. However, smokers must correctly change/fill cartridges and charging is required for the new generation products.

\subsubsection{Clonidine}

Given that anxiety is a symptom of nicotine withdrawal following smoking cessation [112], it has been proposed that the anxiolytics clonidine, a noradrenergic agonist, may be a possible smoking cessation treatment $[113,114]$. Following evidence for its safety and efficacy, clonidine hydrochloride is now recommended as a second-line agent, but is not approved by the Food and Drugs Administration or any other drug regulatory body as a smoking cessation aid [115].

\section{Relative efficacy}

Studies have shown that clonidine relieves cravings, anxiety, restlessness and tension [113, 114]; and appears to promote smoking cessation, with beneficial effects particularly among those with high levels of anxiety [116]. A randomised clinical trial in 1988 with smokers who had failed in previous attempts to stop smoking reported that cessation success rates in clonidine treated subjects (verified by serum cotinine concentration) was more than twice that in placebo-treated participants [113]. The same year, another randomised placebo-controlled trial with forty cigarette smokers reported that clonidine treatment ameliorated short-term withdrawal symptoms, especially cravings, and that there was a trend towards a reduction in the number of cigarettes smoked [117]. However, another randomised trial with nearly two-hundred subjects failed to report a benefit on withdrawal symptoms, quitting or smoking reduction in a primary care setting [118].

\section{Relative safety}

Clonidine has adverse effects associated with its use: postural hypotension, dizziness, dry mouth, sedation, sleep disturbances, depression, and constipation [116]. Although these are also classic 
withdrawal symptoms and may not result from drug use, this has resulted in the avoidance of clonidine by many clinicians [119].

\section{Relative cost}

Oral dosing of clonidine is relatively inexpensive ( $<\$ 1$ per day) compared to NRT or bupropion which cost more than $\$ 3.00$ per day [120]. Thus if clonidine is deemed as effective as the first-line treatments it is likely to result in a reduction in health care costs.

\section{Relative use}

Although clonidine is not currently licensed as a smoking cessation aid, and its side-effects mean that is it unlikely to compete with the currently available first-line treatments, it is regarded as second-line treatment in a number of countries.

\section{Relative scope}

Clonidine may be particularly useful for those with anxiety problems and appeal to smokers who do not wish to use nicotine-based medications to make a quit attempt, or who have previously tried unsuccessfully to quit with other pharmacotherapy. However, many smokers are adverse to using a drug associated with treating psychiatric conditions [112]. Caution is also advised when coadministering clonidine with beta-blockers, calcium channel blockers and digitalis [116].

\section{Relative ease of use}

The regimen is similar to that for the prescription first-line treatments and clonidine is also available as a patch which may increase adherence rates [121]. Patch formulations of smoking cessation medications are discrete, provide a steadier supply of the drug, and can be simpler to use than oral formulations.

\subsection{Alternative Products: unclear efficacy}

\subsubsection{Venlafaxine}

Smoking is particularly high among those suffering from depression, thus anti-depressants may be a suitable pharmacotherapy for smoking cessation for such individuals [122]. Venlafaxine, an Serotoninnoradrenaline reuptake inhibitor (SNRIs), inhibits neural 5-HT, noradrenaline and dopamine reuptake, and is used in the treatment of depression and anxiety disorders [86].

Relative efficacy 
Preliminary evidence also suggests that venlafaxine may have therapeutic effects when combined with NRT through its influence on improved memory and reduction in depressive symptoms [123]. In a study of nearly one hundred and fifty smokers randomly assigned to Venlafaxine plus NRT or placebo plus NRT in conjunction with behavioural counselling, venlafaxine did not appear to increase the propensity to quit smoking. However, this trial suggested that there may be benefits for lighter smokers and a reduction in negative affect was noted [124].

\section{Relative safety}

Side effects of SNRIs are greater than for SSRIs and bupropion and include muscle spasms/twitching, profuse sweating and dizziness $[125,126]$. Controlled trials assessing the use of venlafaxine for the treatment of depression have noted excessive weight gain and sexual dysfunction [127]. Cardiac electrophysiological effects with venlafaxine have also been observed in guinea-pig cardiac myocytes [128]. However, venlafaxine does have a more benign side effect profile than older anti-depressants.

Relative cost

The cost for six months treatment of venlafaxine for depression is similar to bupropion at around f1530 (US\$ 2213) [129], and therefore significantly more than for NRT. Its cost-effectiveness for smoking cessation and harm reduction has not been assessed.

\section{Relative use}

SNRIs greater number of side effects means that they are unlikely to be licensed as smoking cessation aids, unless efficacy is proved to be substantially greater than for first-line treatments.

\section{Relative scope}

Due to its anti-depressive properties, venlafaxine may be an appropriate medication for those with comorbid depression diagnoses. However, its inability to mimic the sensory and behavioural components of smokers, and greater side-effects compared to the medications discussed so far, may limit its use.

Relative ease of use

Dosages of 75 to $375 \mathrm{mg} /$ day administered as 2 or 3 times daily regimens produce significant reductions in depression [130]. If similar levels are used for smoking cessation the regimen is more complex than the single daily dose of either varenicline or bupropion but simpler than for oral NRT.

\subsubsection{Nicotinic acetylcholine receptors (nAChR) antagonists}


Given the proven efficacy of varenicline, a partial agonist of nAChr, it has been suggested that nAChR antagonists may aid smoking cessation [131]. Such drugs include mecamylamine (trade name Inversine), currently approved for the management of hypertension; lobeline, an alkaloid derived from the leaves of an Indian tobacco plant (Lobelia inflate) [75, 132]; GTS-21, a derivative of anabaseine (a product in tobacco), which improves cognitive function and may be a possible novel treatment for dementia [133]; dianicline, a drug developed by Sanofi-Aventis which has a similar pharmacological profile to varenicline; sazetidine specified for the treatment of anxiety and depression; $\mathrm{UCl}-30002$, a negative allosteric modulator of nAChr and agonist of GABA receptors [134]; and AT-1001 [N-(2bromophenyl)-9-methyl-9-azabicyclo[3.3.1] nonan-3-amine], a high-affinity and highly selective ligand at nARhr [135].

\section{Relative efficacy}

Mecamylamine has shown some promising results [136], particularly in women [137]. Lobeline has proved rather ineffective $[75,132]$. The effects of GTS-21 on negative affect, cognition and smoking relapse are currently being investigated in a phase two clinical trial (NCT02432066). Some have argued that it may prove a better treatment option than the nicotine patch [138] and may be particularly beneficial for those with schizophrenia, as it appears to improve symptoms [139]. Clinical development of dianicline has been discontinued after reports of unfavourable results in phase 3 studies (Sanofi Pipeline, 2012). AT-1001 has been found to decrease nicotine self-administration in rats and to be a potent partial agonist with 65-70\% efficacy at human nACHr [140]. UCl-30002 has also been shown to decrease nicotine self-administration [141].

\section{Relative safety}

Lobeline and mecamylamine have significant side effects [75, 132], including drowsiness, hypotension and constipation $[142,143]$. GTS-21 is no more toxic than nicotine and does not appear to affect either autonomic or skeletal muscle systems. Clinical trials suggest that it is well tolerated in large doses [133]. Dianiclin may have a more favourable profile than varenicline [41], while sazetidine has fewer neurologic side effects than other nicotinic agonists [144].

\section{Relative cost}

The cost effectiveness of these products for smoking cessation has not been assessed.

\section{Relative use}

None of these products are licensed for smoking cessation and many are in the early stages of clinical trials, thus it is not possible to predict the likely impact they may have in the future. 
Relative scope

Mecamylamine was original marketed for lowering blood pressure, and so may be particularly beneficial for those with certain cardiovascular conditions. It is easy to use and can be combined with NRT. In fact, the two therapies may offset each other's adverse effects $[136,143]$. GTS-21 has been proposed as a possible treatment option for patients with schizophrenia [145].

Relative ease of use

Dosing is similar to bupropion and varenicline, with a recommended $8 \mathrm{mg}$ tablet once daily of lobeline and a $150 \mathrm{mg}$ twice daily dose of GTS-21 (NCT02432066). However, many smokers are adverse to using oral medication and prefer transdermal product forms.

\subsubsection{Glucose tablets}

Oral dextrose (glucose) has been proposed as a possible aid to smoking cessation. It was hypothesised that glucose tablets could promote abstinence by satiating carbohydrate cravings that ex-smokers often mislabelled as cigarette cravings $[146,147]$. Previous studies have shown that nicotine acts as an acute appetite suppressant by raising blood glucose levels and acting directly on cells in the lateral hypothalamus. The appetite suppressant effect may also be linked to the effects of nicotine on serotonergic pathways in the brain [146].

Relative efficacy

In a randomised controlled trial with nearly one thousand participants, no significant effect of glucose tablets over and above sweet tasting tablets was detected [147]. However, glucose tablets may promote short-term abstinence, particularly when used as an adjunct to NRT or bupropion [147, 148].

Relative safety

Part of their appeal lies in their reduced number of side effects relative to the first-line treatments [146]. When used in small doses, no common side effects have been reported; however, at higher doses allergic reactions have been noted and its use among diabetic patients should be avoided.

\section{Relative cost}

The major advantage of glucose tablets is that they are relatively inexpensive and thus they may be a treatment option for developing countries [146].

Relative use 
Given their lower cost and accessibility the promotion of glucose tablets for smoking cessation would likely increase the overall use of smoking cessation medication particularly in developing countries.

\section{Relative scope}

Glucose is unlikely to interact with other medications and so may be used concurrently [147]. It is freely available and has no contraindications (except some caution should be advised for those with diabetes). This is important given that many smokers are being treated for smoking related morbidities with pharmacotherapy.

\section{Relative ease of use}

Glucose tablets are freely available in shopping outlets, unlike burpoprion and varenicline which are only available on prescription. Recommended daily use is similar to that for NRT [147].

\subsubsection{Nicotine vaccines}

Vaccines targeting nicotine are being developed as a novel approach to treating tobacco dependence. The main mechanism of action is their inducement of anti-nicotine antibodies that bind to nicotine in the periphery, and thus reduce the amount which enters the brain. Vaccines may also have a secondary effect of slowing the rate of nicotine delivery; an important property, as rapid increases in nicotine levels are more likely to lead to addiction than slow kinetics [149]. First-generation formulations were conjugate vaccines, consisting of nicotine linked to a carrier protein and then mixed with alum adjuvant [150]. Modifications and further developments have focused on finding the most effective site of attachment for nicotine, identifying the number of nicotine molecules which need to be linked to each carrier protein, and the composition of the protein itself [150,151]. To increase efficacy, support has been given to the use of multivalent vaccines, i.e. combination of multiple vaccine products and concurrent use with other smoking cessation pharmacotherapy [152]. Animal studies have shown a strong synergistic effect of a nicotine vaccine in combination with the nAChR antagonist mecamylamine [153].

Recently, the first synthetically engineered nanoparticle nicotine vaccine - SEL-068 - designed by Selecta Biosciences Inc, entered a phase 1 clinical trial to evaluate its safety, tolerability and pharmacodynamics profile [154]. As it is fully synthetic, the immune response will focus on nicotine, thus avoiding responses to biological carriers. Alternatives to nicotine vaccines have also been suggested. These include passive immunization, which unlike vaccines does not require weeks to months for the generation of effective levels of antibodies; and gene transfer, which involves the administration of viral vectors containing genes for the expression of drug-specific antibodies [155]. 
First generation nicotine vaccines were shown to clinically reduce the amount of nicotine reaching the brain and to reduce nicotine self-administration behaviours [156-161]. However, these strong preclinical findings were not subsequently mirrored in clinical trials, with overall efficacy for smoking cessation being similar to placebo vaccines [162-164]. This may be a consequence of poor antibody production or vaccine composition. Many vaccines produce nicotine-specific antibody levels not much above $50-100 \mu \mathrm{g} / \mathrm{ml}$, which provides the binding capacity for at most one cigarette [150]. Subgroup analyses have shown that subjects with the highest serum antibody concentrations have double the smoking cessation rates of controls $[163,165]$. It also appears that nicotine vaccine candidates which incorporate hapten enantiopurity may maximize efficacy compared to use of racemic nicotine hapten [166]. However, a recent study concluded that nicotine vaccines do not appear to improve the chances of stopping smoking when given in addition to varenicline and behavioural support [167].

Passive immunization with drug-specific monoclonal antibodies has been shown to block nicotine [153], while preclinical tests on monkeys immunized with increased doses of the synthetically engineered nanoparticle nicotine vaccine SEL-068 showed a robust and dose-dependent induction of high titres of anti-nicotine antibodies with a strong affinity to nicotine [168]. In a recent study, SEL068 was shown to attenuate nicotine's discriminative-stimulus effects in nicotine-experienced monkeys [169].

\section{Relative safety}

The safety profile of vaccines has been confirmed in clinical trials and is likely to be similar to that of other medications, although further surveillance is warranted [170]. In view of the novelty of gene transfers and possible unanticipated toxicities, evidence for long-term safety will be necessary for their development to proceed.

\section{Relative cost}

Although a nicotine vaccination program was not found to be cost-effective for smoking prevention [171], there is some suggestion that vaccines will be less expensive than other smoking cessation treatments [172]. Costs are likely to be higher for passive immunization vaccines, with dosages required which are 10-100 times greater than those widely used to treat cancer or immune disorders [173].

\section{Relative use}

The effect of overall effective medication use is unclear. However, given that the majority of smokers obtain medication over-the-counter [174], the requirement that it be administered by a health-care professional means that few smokers are likely to opt to use nicotine vaccines. 
Relative scope

Nicotine vaccines may be suitable for those with contraindications for other smoking cessation medication. Long-term the treatment regimen for vaccines is simple and they may be preferable for those with poor adherence.

\section{Relative ease of use}

Although multiple injections of the first generation vaccines are required intravenously by a health care professional, they have a prolonged effect on the immune system (for 6-12 months). Passive immunization vaccines in contrast do not require weeks to months for the generation of effective levels of antibodies.

\subsubsection{Drugs that affect gamma-aminobutyric acid (GABA) transmission}

Nicotine stimulates the release of a number of neurotransmitters, including GABA. Thus it has been proposed that medications that affect GABA neurotransmission may be useful as pharmacological treatments for tobacco addiction $[175,176]$. One example is topiramate which inhibits glutamatergic neurotransmission, reduces fast inward voltage-gated sodium currents [177], and enhances GABAergic tone by direct action on GABA-A receptors $[178,179]$. Topiramate is approved for the treatment of epilepsy and has been shown to be efficacious for bipolar disorder, post-traumatic stress disorder and eating disorders (e.g. [180]). Low dose topiramate has also been used in the treatment of alcohol dependence [181]. Three other drugs which may also offer some utility for smoking cessation include zonisamide which is in the same class of medications (marketed as Topamax) [182]; gabapentin, an antiepileptic drug that acts on voltage gated calcium channels (particularly $\mathrm{N}$ and Ltypes) and binds to GABA-B receptors to inhibit their function[183, 184]; and tiagabine, a blocker of GABA reuptake (marketed under Gabitril) $[185,186]$.

Baclofen, a selective GABA-B receptor agonist, was recently proposed in response to the observation of a co-occurrence between alcohol and nicotine use. Approximately half of the population who are dependent on alcohol smoke, $75 \%$ of whom require treatment for both dependences $[187,188]$. Up until this point, drugs to tackle both addictions had proved unsuccessful.

\section{Relative efficacy}

Studies have demonstrated the efficacy of topiramate for smoking cessation, particularly among men and alcoholic smokers [189-191]. An additional benefit may be the prevention of post-cessation weight gain [192]. In a recent 10-week trial, topiramate resulted in higher quit rates than a placebo and significant decreases in weight [193]. Zonisamide also appears promising. Its combination with 
varenicline increases smoking quit rates and decreases nicotine withdrawal and craving relative to varenicline alone [182]. Studies on tiagabine suggest that it may reduce the rewarding effects of nicotine and improve cognitive performance in abstinent smokers [185].

A number of studies have provided clinical and preclinical evidence that baclofen is a successful treatment for both tobacco addiction and alcoholism [175, 194]. A recent randomized placebocontrolled pilot trial demonstrated a significant reduction in craving and smoking [195]; while another that baclofen significantly increased the percentage of days of abstinence from alcohol and tobacco co-use [196]. A further trial was terminated due to difficulties in recruiting an appropriate sample (NCT01228994).

In pre-clinical trials gabapentin was shown to attenuate withdrawal symptoms and increase shortterm abstinence [197]. However, two small scale trials showed little promise of gabapentin for treating smoking cessation $[198,199]$. This was confirmed in a recent proof-of-concept pilot study [200].

Safety

In general, the safety and tolerability of GABA-based drugs have been confirmed [195]. However, they may be liable to abuse [201] and have side effects including sedation, dizziness, weakness, and fatigue [195]. In a trial of twelve smokers treated with topiramate additional side-effects including slurred speech, depressive symptoms and fatigue were noted and three subjects interrupted treatment due to intolerable symptoms [202]. Zonisamide is slightly better tolerated than topiramate and does not produce the negative cognitive effects that are evident following topiramate administration [203, 204]. However, those using antiepileptic drugs, such as tiagabine, may be at risk of developing severe neuropsychiatric symptoms [205].

Relative cost

Topiramate and Gabapentin costs less than $f 4$ (US \$6) a week compared with at least $f 9$ (US \$14) for NRT $[206,207]$.

Relative use

It is currently unclear whether GABA-based drugs would increase the overall use of effective medication. Although cheaper than nicotine-containing products they would likely not be available over-the-counter.

\section{Relative scope}

GABA-based drugs may be useful for smokers who wish to prevent post-cessation weight gain and may act as a concurrent treatment for epilepsy, migraines, some psychiatric conditions and eating 
disorders (conditions for which they were originally indicated). Baclofen may be suitable for those with co-existing alcohol use disorders.

Relative ease of use

Many GABA-based drugs, including baclofen, must be taken every 4-6 hours and preferably with clinical supervision to ensure compliance [194-196]. Thus they do not appear to be easier to use than currently available drugs which are administered orally. Although extended-release formulations have been produced for multiple sclerosis patients, these have not received approval for smoking cessation (NCT01457352).

\subsubsection{Drugs that affect N-methyl-D-aspartate (NMDA) receptors directly or indirectly}

The finding that one of the effects of nicotine on the body is at the level of NMDA receptors in the brain motivated investigations into drugs which affect these receptors. Four drugs have been, or are currently being, assessed in clinical trials which appear to directly affect NMDA receptors: memantine, a non-competitive, selective NMDA receptor antagonist used in the clinical treatment of dementia (NCT00136786 still running), GW468816, a competitive antagonist at the glycine site [208], and the NMDA receptor partial agonist cycloserine (NCT01062932 in 2012). Gabapentin (discussed already) also directly inhibits NMDA receptors and potentiates the effect of NMDA channel blockers [209-211].

A further drug, $\mathrm{N}$-acetylcysteine [212], has an indirect effect through the release of glutamate from glia into the extra-synaptic space via the cysteine-glutamate antiporter [213]. This increased basal glutamate activates type II/III metabotropic glutamate receptors (also extra-synaptic), which supresses the release of synaptic glutamate [214], thereby reducing NMDA receptor activation. Furthermore, $\mathrm{N}$-acetylcysteine is a precursor for gamma-glutamylcysteinslycine, which has been shown to potentiate NMDA receptor responses $[215,216]$. $\mathrm{N}$-acetylcysteine also stimulates the release of dopamine [217], which is argued to play a major role in drug addiction [218].

\section{Relative efficacy}

Memantine has demonstrated some efficacy for other dependencies including opioid use [219]. However, in a small study of 20 smokers, memantine failed to facilitate smoking reduction [220]. Despite preclinical data being promising for GW468816, no effect on relapse or lapse rates have been reported relative to placebo [208]. Initial studies on cycloserine provided some support for its use with cue exposure therapy in attenuating conditioned reactivity to smoking cues [221], but further development hinges on the results from the clinical trial. Finally, a pilot study exploring the effect of $\mathrm{N}$-acetylcysteine has shown encouraging trends [212]. A recent review on the potential role of $\mathrm{N}$ acetylcysteine in the management of substance use disorders concluded that it shows promise in 
terms of safety, tolerability, and potential efficacy for promoting abstinence from cocaine, nicotine, and cannabis [222].

Relative safety

Although higher-affinity NMDA-related drugs can produce severe adverse neurotoxic and psychogenic effects in humans, and lower affinity drugs are likely to have a greater number of side-effects than NRT, data across a range of clinical applications has shown that NMDA-based drugs are safe and welltolerated [223].

Relative cost

NMDA-related drugs are a similar price to NRT. For example, twenty-eight tablets of $10 \mathrm{mg}$ memantine costs around f34.50 (US\$ 39) [224].

Relative use

It is currently unclear whether NMDA-related drugs would increase the overall use of effective medication. If only available on prescription, use is unlikely to cannibalise the NRT market.

Relative scope

NMDA-related drugs were initially indicated for Alzheimer's disease, having a significant positive effect on cognition and behaviour. NMDA based drugs also have anti-anxiolytic and anti-depressant effects, so may be a suitable treatment for smokers suffering from mood disorders [225].

Relative ease of use

Drugs targeting NMDA receptors are administered orally, but generally require only one tablet per day. Dosing routines are therefore simpler than for oral NRT but similar to varenicline and bupropion. However, many smokers are adverse to using oral medication and prefer transdermal product forms.

\subsubsection{Dopamine agonists}

As mesocorticolimbic dopamine systems mediate the reinforcement effects of nicotine [226], researchers have hypothesised that drugs traditionally used to treat Parkinson's disease and appetite control disorders which affect dopamine receptors may be potential targets. Viable candidates for clinical investigation are levodopa [227], bromocriptine, GSK598809, the cognate analog GSK618334 and BP1.4979 developed by the Bioproject.

Relative efficacy 
Preliminary evidence in rats suggests levodopa may aid in preventing post cessation weight gain by diminishing dopaminergic responses to external stimulation [228]. Levodopa does not appear to promote abstinence or withdrawal symptom relief [227]. Bromocriptine has been shown to decrease cigarette craving and reduces smoking rates in humans $[229,230]$.

Animal studies have shown that GSK598809 decreases nicotine seeking behaviour and nicotine cravings [231]. Phase 1 and phase 2 trials have since been conducted with human participants, but with mixed results. One clinical trial found that a $75 \mathrm{mg}$ dose alleviated craving in smokers after 14 hours of overnight abstinence. It also partially reversed attentional bias, though such effects were not maintained at later time points (NCT00437840 in 2008). In another trial, which included a placebo control group, a single dose of GSK598809 did not reduce the reinforcing value of smoking and nicotine when measured using the Behavioural Economic Task and Cigarette Choice Paradigm. In fact, when smokers were allowed to smoke freely, those who had received the active drug had higher cigarette consumption, suggesting some compensatory behaviour (NCT00605241 in 2012). GSK598809 was also recently tested in a third trial as an add-on to cognitive behavioural therapy and nicotine patch replacement therapy for the prevention of very early relapse from smoking in severe chronic smokers (NCT01188967 in 2014). Due to the potential cardiovascular liability at high doses, each patient in the trial was required to use an ambulatory monitor, which was a significant hurdle to recruitment. The results of this trial have yet to be reported.

GSK618334 entered clinical trials around the same time, in 2007 (NCT00513279 in 2010, NCT00814957 in 2009, NCT01036061 in 2011). These focused on its safety profile and pharmacokinetics, showing promising results. However, the drug has yet to be tested as a smoking cessation aid. A phase 2 clinical trial assessing the efficacy and safety of BP1.4979 for smoking cessation was completed at the beginning of 2015 (NCT01785147 in 2015), but results have yet to be published.

\section{Relative safety}

Many new drugs which target dopamine receptors have possible cardiovascular liability at high doses. Suitable data on the safety profile of drugs which target dopamine receptors is currently unavailable. Side effects of bromocriptine and levodopa have hindered their recommendation for smoking cessation [232].

\section{Relative cost}

Potential costs of these new drugs which target dopamine receptors are unclear. Previous studies have reported that dopamine agonists cost significantly more than other medications which have been tested as smoking cessation aids [233]. 


\section{Relative use}

It is unclear whether these novel drugs which target dopamine receptors will increase the overall use of smoking cessation aids. Currently evidence regarding efficacy is mixed, which, in addition to their likely high cost, may hinder use.

\section{Relative scope}

New drugs targeting dopamine receptors may be effective for the concurrent treatment of alcohol dependence and for those who wish to prevent post-cessation weight gain [234].

Relative ease of use

New drugs targeting dopamine receptors are available in dosages of $60 \mathrm{mg}$ to $175 \mathrm{mg}$ tablets. Thus, the regimen will likely consist of one tablet per day which is less than that for oral NRT. However, many smokers may not wish to use oral medication and prefer transdermal product forms.

\subsubsection{Noradrenaline reuptake inhibitors}

Preclinical and clinical studies suggest that noradrenaline contributes to the mediation of the subjective effects of tobacco [235]. The noradrenaline reuptake inhibitor atomoxetine (marketed as Strattera), used in the treatment of attention deficit disorder, may thus be a useful aid for smoking cessation [236]. Atomoxetine causes noradrenergic augmentation in the prefrontal cortex [237]. The alpha- and beta-adrenergic receptor blockers carvedilol (marketed as Coreg and Dilatrend) and labetalol have also been suggested as harm reduction treatment options for tobacco dependence given that they may dampen the cardiovascular response to nicotine [238]. Reboxetine, a selective noradrenaline uptake inhibitor prescribed as an antidepressant, was also advocated as a possible treatment option [239]. Although reboxetine received preliminary approval by the FDA in 1999 as an antidepressant, due to its positive pharmacological profile and lack of side effects, its development has been halted [240].

\section{Relative efficacy}

Trials using clinical populations (psychiatric patients, non-psychiatric patients and patients with attention deficit hyperactivity disorder) show tentative support for the possibility that atomoxetine may reduce cigarette consumption and/or smoking behaviours [236, 241, 242]. In healthy populations, atomoxetine has been found to reduce the number of cigarettes smoked, but does not result in lower salivary cotinine levels relative to placebo [243]. A recent RCT which aimed to assess atomoxetine's effects on nicotine response and stress response in smokers was suspended due to a lack of funding (NCT02046551). 
Carvedilol and labetalol treatment has been found to attenuate nicotine-induced increases in heart rate and blood pressure $[244,245]$. Attenuation of tobacco withdrawal symptoms has been noted for high-dose labetalol treatment relative to placebo [245]. In contrast, the use of carvedilol alone or in combination with nicotine lozenges does not appear to affect withdrawal symptoms [244]. Carvedilol may also aid in the treatment of the physiological effects of smoking cessation, such as tremor and cough, by preventing or suppressing mucus hypersecretion [246].

Reboxetine has been found to attenuate nicotine self-administration in rats by over $60 \%$ [247], and to have an adaptive modification of the function of the selective noradrenaline transporters [248]. A patent has been approved to assess the use of an effective amount of reboxetine in combination with the administration of a smoking-cessation enhancing agent (e.g. NRT and an opioid antagonist) [249].

\section{Relative safety}

As atomoxetine does not raise concentrations of dopamine in the prefrontal cortex, it has low abuse potential, a finding that has been supported in clinical trials [237]. However, it is not well tolerated by healthy adults at high doses [243]. There are several clinical situations in which atomoxetine should be closely monitored or not taken including for patients who have a history of narrow angle glaucoma, cardiovascular problems, epileptic seizures, Tourette's syndrome, urinary obstruction, or who are pregnant [250]. Carvedilol is also contraindicated for a long list of conditions including, but not limited to, bradycardia, sick sinus syndrome, hepatic dysfunction, obstructive airways disease, severe hypotension, metabolic acidosis and phaeochromocytoma [251]. The safety and efficacy of once-daily carvedilol ( 25 or $50 \mathrm{mg}$ ) appears to be comparable to that of twice-daily labetalol (200 or $400 \mathrm{mg}$ ) [252]. Reboxetine is well tolerated by adults and the elderly during short- and long-term treatment for depression [253].

\section{Relative cost}

On the assumption that a one $40 \mathrm{mg}$ tablet of atomoxetine would be taken for 21 days [243], the cost would be in excess of $£ 45$ (US\$ 65) per smoker for a three week period [254]; which is similar to the cost of many of the first-line treatments. Carvedilol and labetalol are much cheaper at around $£ 0.06$ per day (US\$0.09) [255].

\section{Relative use}

It is unclear whether any of these drugs will increase the overall use of smoking cessation aids. However, given the current lack of evidence for their efficacy, they are unlikely to monopolise the smoking cessation market. 


\section{Relative scope}

Given their original indication, atomoxetine may be beneficial for those suffering concurrently with attention deficit disorder and carvedilol for those with mild to severe congestive heart failure, left ventricular dysfunction and following a heart attack. However, there are several contraindications which need to be considered.

Relative ease of use

One tablet once or twice a day reflects the dosing profile of the first line treatments varenicline and bupropion. However, many smokers are adverse to using oral medication and prefer transdermal product forms.

\subsubsection{PPARY agonists}

Down-regulation of pulmonary epithelial peroxisome proliferator-activated receptor gamma (PPARY) by cigarette smoke promotes inflammatory pathways and contributes to chronic obstructive pulmonary disease (COPD) pathogenesis. Thus, it has been proposed that PPARY agonists, such as pioglitazone (Actos) and OMS405 (originally OMS403), may be a suitable pharmacotherapy for harm reduction [256].

Relative efficacy

A preclinical trial of OMS405 for smoking withdrawal was conducted in the US in 2009 and a phase 2 clinical trial in 2010 [257]. Although the results have yet to be released, the patent literature reports a decrease in smoking behaviour in a manner similar to varenicline [258]. There is also evidence for a possible harm reduction indication for the drug. PPARY agonists reverse the down-regulation of PPAR $\gamma$ through a number of pathways and help to improve symptoms of COPD, a disease which is largely due to smoking [259]. PPARy agonists are currently also being assessed for their possible chemo-protective effects in relation to lung cancer [260].

Relative safety

OMS405 appears to have a good safety profile and can be used concurrently for the treatment of diabetes [261]. Water retention is a common side effect with other PPARY based drugs and licensing cautions the use with patients diagnosed with cardiac disorders. Its safety relative to other smoking cessation aids is currently unclear [262].

Relative cost 
A daily dose of $30 \mathrm{mg}$ OMS405 costs around $f 9$ (US\$ 13) a week, which is similar to the cost of NRT but cheaper than varenicline [263].

Relative use

It is unclear whether OMS405 will increase the overall use of smoking cessation aids. If it is less expensive and provides protective effects against inflammation it may have potential as a harm reduction product.

Relative scope

OMS405 was initially indicated for metabolic diseases, and thus may be a suitable treatment option for smokers diagnosed with diabetes.

Relative ease of use

OMS405 involves a daily $30 \mathrm{mg}$ dose, which is an easier routine than oral NRT products. However, many smokers may be adverse to using oral forms and prefer transdermal product.

\subsubsection{Lorcaserin}

Lorcaserin hydrochloride (marketed as BELVIQ and Lorqess) was approved in June 2012 by the Food and Drug Administration as an adjunct to a reduced-calorie diet and physical activity for chronic weight management. It is believed that lorcaserin decreases food consumption and promotes satiety by selectively activating 5-HT receptors in the brain [264]. It may thus be a suitable pharmacotherapy for smokers wishing to prevent post-cessation weight gain. A patent has recently been submitted to create a nutritional supplement for smoking cessation in which it is proposed that lorcaserin may be a main ingredient with the aim of increasing 5-HT levels and assisting in maintaining body weight [265]. In addition, lorcaserin used alone or combination with varenlicine may be a novel agent for smoking cessation given that 5-HT systems play key roles in the action of nicotine [266].

\section{Relative efficacy}

In preclinical studies, lorcaserin was found to decrease nicotine self-administration and nicotineenhanced responding for conditioned reinforcement in rats [266-268]. A recent phase 2 clinical trial found that lorcaserin was associated with a significantly higher continuous quit rate compared with placebo. In addition, a reduction in bodyweight was also observed [269, 270]. A further phase 2 clinical trial is currently being conducted to assess the effect on urges to smoke, withdrawal symptoms, reinforcing effects of smoking and eating behaviour, in addition to body weight and abstinence (NCT02044874 still running). 


\section{Relative safety}

Treatment with lorcaserin is well tolerated, with the most common adverse reactions observed being headache, dizziness, fatigue, nausea, dry mouth and constipation [269, 270]. However, neuropsychiatric and cognitive-related adverse events are frequent, and although no imbalance in reported cancer incidence in smokers is seen, mammary tumours have been found in rats treated with lorcaserin [271].

Relative cost

Lorcaserin has not been deemed a cost-effective weight loss strategy and costs substantially more (US\$1,743 for full treatment) than traditional smoking cessation aids [272].

Relative use

The overall effect on effective medication use is unclear, but the high costs will likely limit its distribution.

\section{Relative ease of use}

Tested dosage in the clinical trial was $10 \mathrm{mg}$ lorcaserin once or twice daily which is similar to the dosing regimen of other smoking cessation medications [269]. It is currently only available in oral form which may not be suitable for all smokers.

\subsection{Alternative Products: no efficacy}

\subsubsection{Other anxiolytics}

Given the evidence for clonidine other anxiolytics have been proposed as possible aids to smoking cessation including buspirone (trade name Buspar), a non-benzodiazephine anxiolytic with effects on 5-HT neurotransmission; ondansetron (trade name Zofran), a5-HT3 receptor antagonist; and diazepam (first marketed as Valium) and meprobamate (marketed as Miltown and Equanil among others), which are tranquillisers. Beta-blockers also have potential anxiolytic effects and have been advocated. The idea behind the use of anxiolytics is that they moderate anxiety experienced from withdrawal symptoms and increase the main neural transmitters that play a major role in nicotine dependence [112].

\section{Relative efficacy}

As a whole, the findings from clinical trials suggest these medications have little effect on smoking cessation [86, 112]. For example, the rate of smoking abstinence has been reported to range from $36 \%$ to $88 \%$ and $16 \%$ to $89 \%$ in buspirone and placebo treatment groups, respectively. However, these 
medications may have some effects on urges to smoke [273]. In a double-blind, randomised, placebo controlled trial, with forty long-term cigarette smokers, Buspirone ameliorated short-term withdrawal symptoms associated with smoking cessation [274]; while animal studies have demonstrated that ondansetron is effective in decreasing cravings [275]. Research into their utility has in recent years diminished due to the claim that the role of anxiety in smoking may have been overplayed [112].

\section{Relative safety}

Although many of these medications have significant side effects, such as risk of abuse and sedation [5], some have more favourable profiles: buspirone was advocated as it lacks abuse liability and does not promote dependence [276]. In a double blind, placebo controlled trial with around one hundred smokers, 4 week treatment with ondansetron was not associated with any severe side-effects [277]. In nine-hundred and eighty-four patients with generalised anxiety disorder who received buspirone in double-blind studies, the incidence of drowsiness did not differ significantly to that reported in placebo participants. Side-effects which did occur significantly more frequently include dizziness, headache, nervousness, light-headedness, paraesthesia and excitation [278].

\section{Relative cost}

It is likely that these products will be a similar price to clonidine and therefore cheaper than NRT [120]. A recent cost-effectiveness analysis of treatments for anxiety disorders found that benzodiazephines (like buspirone) were more cost-effective than tricyclic antidepressant drugs [279].

\section{Relative use}

Given their lack of efficacy and side effects, there is little justification for licensing them as smoking cessation aids.

\section{Relative scope}

These products may be particularly useful for those with anxiety problems and appeal to smokers who do not wish to use nicotine-based medications to make a quit attempt, or who have previously tried unsuccessfully to quit with other pharmacotherapy.

\section{Relative ease of use}

The regimen is likely to be similar as that for other first-line prescription medication, such as bupropion. Unlike NRT, they are only available in oral form and so may not be suitable for all smokers.

\subsubsection{Selective serotonin reuptake inhibitors (SSRIs)}


The SSRIs fluoxetine, paroxetine, sertraline, citalopram, and zimeledine (first-line treatments for depression) have been proposed as possible smoking cessation aids given that dysphoria, depressed mood, and a history of major depressive disorder, are related to uptake of smoking and a failure with attempts to quit [122]. The neurotransmitter 5-HT also plays a major role in nicotine's addictive effects [280].

\section{Relative efficacy}

Long-term trials of SSRI's and some short-term trials have failed to show efficacy in relation to smoking cessation among those with and without a diagnosis of depression [86, 281, 282], although there is some evidence to support the efficacy of sequential treatment (16 week treatment starting 8 weeks prequit) relative to standard treatment (10 week treatment starting 2 weeks prequit) [283]. A randomised placebo controlled trial found no evidence that fluoxetine treatment when used as an adjunct to NRT is effective, but that there may be an advantage to using it in depressed patients [284]. In another study, sertraline treatment produced lower self-reported withdrawal symptoms less irritability, anxiety and restlessness relative to placebo. However, abstinence rates did not differ [285].

\section{Relative safety}

Some side effects have been reported for the use of SSRIs for smoking cessation, particularly at high doses, including amblyopia (dimness of sight), gastrointestinal disorders, nausea, palpitations and tremors $[284,286]$. Treatment with SSRIs has also been associated with emotional detachment, although controversy still exists on this issue [287]. SSRIs may have slightly more side effects than bupropion, including sexual dysfunction and weight gain [287].

\section{Relative cost}

There are currently no reports on the cost-effectiveness of SSRIs for smoking cessation; however, they do appear to be more cost-effective than the tricyclic antidepressants mentioned above when used to treat depression [288-290].

\section{Relative use}

SSRIs lack of efficacy for smoking cessation relative to the first-line treatment bupropion means that they are unlikely to be licensed for use as an aid to smoking cessation.

\section{Relative scope}

Given that SSRIs are first-line treatments for depression, they may be particularly suitable for smokers with a co-morbid diagnosis. However, evidence for their lack of efficacy means that they are unlikely 
to be indicated for such purposes. Many smokers may also be adverse to using a drug associated with treating psychiatric conditions.

Relative ease of use

The dosing regimen of SSRIs is similar to that for other anti-depressants, including bupropion. However, unlike NRT, they are only available on prescription and do not address the sensory and behavioural components of smoking.

\subsubsection{Silver acetate}

Silver acetate use for smoking cessation is analogous to disulfiram for alcoholism being based on the principles of aversive conditioning. It works by producing an unpleasant metallic taste in the mouth when used in combination with smoking [291].

\section{Relative efficacy}

Although a possible effect in promoting cessation has not been disproved, any such effect is likely to be small, and less than that for NRT [291]. In a randomised trial of over five hundred participants, abstinence rates was higher in the silver acetate group compared to those receiving nicotine gum or ordinary gum but only among those with a lower weighted packyear consumption [292].

Relative safety

Excessive ingestion causes a rare condition called argyrism. Thus, a dose no greater than $756 \mathrm{mg}$ is recommended [291]. In randomised controlled trials side effects appear to be similar to that of nicotine replacement and are generally mild and transient, with the most common one being mouth irritation [292].

Relative cost

Its lack of efficacy means it is unlikely to be a cost-effective product for smoking cessation.

\section{Relative use}

Failure to show a beneficial impact on smoking cessation, its mechanism of action, and concerns over safety, means that silver acetate is highly unlikely to be licensed as a smoking cessation aid.

\section{Relative scope}

A particularly appealing aspect of silver acetate for smokers is its availability in both lozenge, gum and spray forms. However, its main mode of action, aversive taste, may be unappealing to some. There are also limits on the length of time it can be used, with the need to avoid argyrism [291]. 
Relative ease of use

Use is similar as for NRT: $2.5 \mathrm{mg}$ lozenge, $1.6 \mathrm{mg}$ gum, or $756 \mathrm{mg}$ spray used up to six times per day for three to six weeks. This is considerably more than for buproprion and varenicline and may thus adversely affect adherence rates.

\subsubsection{Nicobrevin}

Nicobrevin contains four 'active' ingredients (quinine, menthyl valerate, camphor and eucalyptus), and was claimed to provide sensory relief following smoking cessation [293]. There does not appear to be a clear mechanism of action for the use of menthyl valerate as a component of an anti-smoking preparation [294]. There is some evidence that cigarette smoking may have an effect on quinine pharmacokinetics [295], while oral camphor has been claimed to have carminative properties and eucalyptus is often used as a decongestant [294].

\section{Relative efficacy}

There is no evidence long-term that use of Nicobrevin can aid smoking cessation and insufficient evidence to support the efficacy of any of four ingredients it contains [293,294]. Although it may be the case that it has effects on the respiratory and digestive systems, which may relieve some of the symptoms that smokers experience when quitting, any such benefits are eroded from the slightly higher relapse rates in actively treated groups $[291,294]$. There have been no clinical trials comparing the use of Nicobrevin to the first-line treatments.

Relative safety

Concerns have been raised over the health implications of excessive quinine consumption in cigarette smokers [294]. Toxicity with camphor has been reported, while eucalyptus consumption is associated with nausea and vomiting [294]. Side effects associated with Nicobrevin include visual problems, skin irritation, and convulsions [294].

\section{Relative cost}

Nicobrevin is no longer available as a smoking cessation aid in a number of countries, and there is no evidence on its cost-effectiveness.

\section{Relative use}

Around 1 million packs of Nicobrevin were sold between 1992 and 1997. This number dropped to 6,600 packs between 2003 and 2008, while just 200 packs were sold in the subsequent two years 
[294]. Following concerns over its safety, it has since been withdrawn in a number of countries, including the UK [294].

Relative scope

It lack of efficacy and withdrawal from the market in a number of countries means it is unlikely to be a suitable aid for smoking cessation.

Relative ease of use

Its oral formulation and dosing regimen means it is easier to use than some NRT products, however, some smokers may be adverse to taking medication orally. A 28 day course of $10 \mathrm{mg}$ tablets is generally recommended, starting with 1 pill in the morning and two at night.

\subsubsection{Modafinil}

Modafinil is marketed as a wakefulness-promoting agent for those who experience excessive sleepiness, including narcolepsy [296]. Its mechanism is elusive but involves the stimulation of histamine, noradrenaline, 5-HT, dopamine, and orexin systems in the brain [297].

\section{Relative efficacy}

Modafinil has demonstrated significant efficacy in cocaine dependence [150], and studies have shown its potential for alleviating tobacco withdrawal symptoms [298]. Subsequently, it was assessed for the treatment of smoking cessation [299], but the trial was terminated due to the detrimental effect of the drug. In the trial, quit rates did not differ among those who received modafinil relative to placebo, while smoking consumption was $44 \%$ higher in non-abstainers in the intervention arm. In another study, modafinil alone or in combination with nicotine lozenges did not affect tobacco withdrawal symptoms [300], although preliminary results from another study suggest that combining modafinil with transdermal NRT could provide complimentary effects [301].

\section{Relative safety}

Modafinil increases heart rate and systolic blood pressure so is likely to be contraindicated for those with cardiovascular disease. In one cross-over randomised trial, with nineteen participants increases in negative affect and withdrawal symptoms were noted [302]. An increase in baseline heart rate and systolic blood pressure was also noted.

Relative cost 
A course of modafinil is around $f 120$ (US\$ 176) compared with around $f 164$ (US\$ 240) for varenicline. It is thus substantially more expensive than a course of NRT and so is unlikely to be deemed costeffective given its lack of efficacy [303].

Relative use

As modafinil has significant side effects and lower efficacy than traditional smoking cessation aids it is unlikely to be licensed as an aid to smoking cessation or harm reduction.

Relative scope

Modafinil may be suitable for smokers who also suffer from sleep disorders (its original indication), but may be contraindicated for those with cardiovascular disease.

Relative ease of use

Dosing usually requires a daily load of $200 \mathrm{mg}$. Thus the dosing regimen in easier than oral NRT but similar to bupropion and varenicline. Some smokers may however be adverse to taking medication orally.

\subsubsection{Monoamine oxidase inhibitors (MAOI)}

One factor which may account for the association between depression and smoking is monoamine oxidase (MAO), an enzyme first discovered over 40 years ago. Tobacco smoke contains MAOIs which act synergistically with nicotine to enhance addition potential. This is evidenced by smokers having lower levels of MAO compared with non-smokers [304]. Thus, it has been proposed that MAOls, such as moclobemide, selegiline, lazabemide, and EVT302, may have synergistic beneficial effects on depression and smoking cessation.

\section{Relative efficacy}

Trials of moclobemide and selegiline when combined have failed to show efficacy for smoking cessation [86]. However, genetic markers in cholinergic loci in the 15q24 chromosomal region have been proposed to affect response and thus it may be possible to identify those likely to benefit from treatment [305].

\section{Relative safety}

MAOIs are contraindicated for bupropion use [306]. Selegiline is well tolerated by smokers [307], and does not have any serious adverse effects $[305,307]$. In a recent double bind parallel group trial with over two hundred smokers, selegiline compliance was high and there was no evidence of an effect on 
depressive symptoms [308]. When moclobemide is taken in similar doses to that used to treat depression, the major side-effect is insomnia [309].

\section{Relative cost}

Given their lack of efficacy, MAOIs are unlikely to be cost-effective treatment options for smoking cessation. Patch formulations of selegiline cost approximately US\$600/month for treatment, which is substantially more than SSRIs [310].

\section{Relative use}

Given the lack of current evidence for their efficacy, it is unlikely that MAOIs will be licensed for smoking cessation. They are also not a first-line treatment option for depression.

\section{Relative scope}

If they had been shown to be effective, MAOIs would be appropriate for those with a co-morbid depression diagnosis and have fewer side effects than other antidepressants [86].

Relative ease of use

A transdermal form of selegiline, approved for the treatment of depression by the Food and Drug Administration, may be appropriate for those adverse to oral formulations [305]. Similar dosing profiles are required as for the other antidepressants, including bupropion [86].

\subsubsection{Opioid antagonists}

The promotion of opioid antagonists naltrexone, naloxone and buprenorphine was based on the idea that the reinforcing properties of nicotine may be mediated by the release of neurotransmitters which impact on the endogenous opiate system [311]. Naloxone is routinely administered to reverse the effects of narcotic overdose and naltrexone to blunt certain effects of narcotics, while buprenorphine reduces withdrawal symptoms following opioid discontinuation. A controlled-release formulation of naltrexone is approved to treat opioid and alcohol dependence in the US [312].

\section{Relative efficacy}

Research to date suggests that opioid antagonists do not promote smoking cessation, while results are mixed for effects on withdrawal symptoms, the hedonic effects of smoking, and cigarette consumption [311]. However, generally positive effects on post-cessation weight gain have been reported [313]. Concurrent use of buprenorphine and bupropion does not significantly increase abstinence from tobacco, opioids or cocaine relative to buprenorphine alone [314]. 


\section{Relative safety}

Common side effects of opioid antagonist administration include sedation, dizziness, nausea, constipation and vomiting. Physical dependence and addiction are also clinical concerns [315]. Less frequent side-effects include perceptual distortion, respiratory depression and myoclonus [316].

\section{Relative cost}

Opioid antagonist costs and availability vary widely in both developing and developed countries. The median cost of opioid antagonists as a percentage of GNP per capita per month are $36 \%$ for developing nations and 3\% for developed nations [317]. Their cost effectiveness for smoking cessation is relatively unknown, however, given their lack of efficacy to date they are unlikely to be more cost-effective than first-line treatments.

\section{Relative use}

The current lack of evidence for their efficacy in relation to smoking cessation, and concerns over possible dependency and side effects means that they are unlikely to be licensed as smoking cessation aids.

Relative scope

Opioid antagonists may be particularly beneficial for those concurrently dependent on cigarettes and opioids (e.g. morphine, heroin and codeine), but are associated with a number of side effect.

Relative ease of use

Opioid antagonists have a similar dosage regimen to varenicline and bupropion. For example, one oral tablet of naltrexone costs between $25 \mathrm{mg}$ and $200 \mathrm{mg}$ per day [315]. However, many smokers are adverse to using oral medication and prefer transdermal product forms.

\subsubsection{Selective cannabinoid type 1 receptor antagonists}

Rimonabant and taranabant, selective cannabinoid-1 receptor antagonists, might restore imbalance in food intake and energy expenditure, which is often altered in smokers [232]. Although they were initially considered by medicines regulatory agencies for both weight loss and smoking cessation [318], rimonabant and taranabant were removed from the US market primarily due to adverse neuropsychiatric effects [319].

Relative efficacy 
Rimonabant and taranabant appear to increase the chances of quitting and they may moderate weight gain, but evidence is inconclusive regarding long-term abstinence [320]. Clinical trials of Rimonabant which began in 2002, have also noted an increase in HDL cholesterol and decreased triglycerides [321]. Relative safety

In 2008 both rimonabant and taranabant were withdrawn by manufacturers, due to links with mental disorders and unacceptable side effects including digestive, nervous, psychiatric, skin and blood vessel disorders [322]. Other side-effects include headache, diarrhoea, insomnia and sinusitis.

\section{Relative cost}

There is no evidence for the cost-effectiveness of these products in relation to smoking cessation due to their removal from the market.

\section{Relative use}

Both rimonabant and taranabant have been withdrawn by manufacturers due to adverse side effects [322]. For weight control, rimonabant has been argued to be within the range of what is generally regarded as cost effective [323].

\section{Relative scope}

Rimonabant and taranabant may be suitable for those smokers wishing to prevent post-cessation weight gain, although side effects are likely to erode any benefits.

\section{Relative ease of use}

Rimonabant in previous studies has been used in a $20 \mathrm{mg}$ dose once per day [320,322], which is similar to that recommended for other first-line treatments requiring a prescription. However, many smokers are adverse to using oral medication and prefer transdermal product forms.

\subsubsection{Supplements (S-Adenosyl-L-Methionine (SAMe) and St John's wort)}

Two supplements have been suggested as possible aids to smoking cessation as a consequence of their effects on biological compounds associated with the addictive effects of nicotine. The first, Sadenosyl-L-methionine (SAMe), is proposed to have anti-depressive properties by causing elevations in dopamine and noradrenaline levels and increases in 5-HT turnover [324]. The second, St John's Wort, is proposed to be a treatment for mild depression by a) inhibiting reuptake of norepinephrine, dopamine, and 5-HT; and b) having affinity for adenosine and GABA receptors [86, 325]. However, SAMe and St John's Wort's utility as treatments for depression have been questioned given the lack 
of evidence for their efficacy relative to placebo [326], likely partially due to their poor bioavailability following oral administration [327-329].

Relative efficacy

Two small trials of St John's wort have failed to detect a significant effect on quit rates or withdrawal symptoms [330, 331]; although there may be some worthwhile benefits for preventing weight gain [330]. One trial of SAMe did not find significantly increased tobacco abstinence rates nor decreased nicotine withdrawal symptoms compared to placebo [332], and evidence is lacking for a dose response [86].

\section{Relative safety}

Treatment with SAMe up to $1,600 \mathrm{mg} /$ day for 6 weeks appears to be safe, well tolerated and with no serious side effects [333]. St John's Wort is not associated with adverse events, but is contraindicated for concurrent contraceptive use, and has mild side-effects including anxiety, dizziness, abdominal bloating and dry mouth [331, 334].

Relative cost

SAMe is relatively expensive compared to NRT, with prices for a $200 \mathrm{mg}$ tablet ranging from $\$ 0.75$ to $\$ 1.25$ [335]. St John's Wort is generally lower in price than other antidepressants such as bupropion [336], thus if it had been deemed effective may be a suitable option for developing countries.

\section{Relative use}

SAMEe and St John's Wort are both available over the counter; however, their lack of efficacy for smoking cessation means they are unlikely to increase overall use of treatments during smoking cessation.

\section{Relative scope}

These products may be suitable for those who are adverse to prescription pharmacotherapy and who are contraindicated for the other medications discussed in this review. They are also well tolerated and have fewer side-effects.

Relative ease of use

SAMe in clinical trials has been used in 400-mg four tablets a day formulations and St John's wort in 300-mg three tablets a day formulations [331, 332]. This may adversely affected treatment adherence relative to the first-line treatments which require one oral dose per day. 


\subsubsection{Other tricyclic antidepressants}

Following the success of bupropion and nortriptyline other tricyclic antidepressants have been advocated, including doxepin and imipramine [86]. Doxepin's structure and general pharmacological properties are similar to imipramine and buproprion, but it also combines a sedative effect with antidepressant activity. Consequently, doxepin is generally used for those with sleep disturbances or depression associated with anxiety.

\section{Relative efficacy}

There are no long term studies of doxepin and imipramine, but short term trials suggest that imipramine does not significantly reduce cigarette consumption compared to a no-medication control [337]. Although doxepin improves cravings, two months sustained abstinence rates are similar to placebo [338].

Safety

Doxepin is generally well tolerated with side-effects which are similar in nature to those of other tricyclic antidepressants (e.g., dry mouth, drowsiness and constipation) [339]. Doxepin tends to cause fewer side-effects than imipramine $[339,340]$ and is well tolerated in the elderly with cardiovascular disease. However, although doxepin causes fewer cardiovascular side-effects than other antidepressants, it has an intrinsic cardiotoxicity on overdosage [339].

\section{Relative cost}

Smoking cessation support with imipramine and doxepin would likely cost a similar amount as treatment with other antidepressants [341]. It has been suggested that doxepin tablets are one of the cheapest treatment options for depression [342].

Relative use

Although these products were once widely used as antidepressants, they have subsequently been replaced by newer antidepressant medications with better side effect profiles [86].

\section{Relative scope}

As with bupropion, tricyclic antidepressants are likely to be particularly useful for those suffering from depression. However, their side-effects would likely limit their use and many smokers may be adverse to using a drug associated with treating psychiatric conditions.

Relative ease of use 
Tricyclic antidepressants have a similar dosing profile to varenicline and bupropion and the tricyclic antidepressant nortriptyline. However, many smokers are adverse to using oral medication to help them quit smoking.

\section{Conclusion}

National guidelines around the world recommend use of evidence-based aids for tobacco dependence to help smokers to quit and/or to reduce their cigarette consumption (e.g. England, America, Brazil, Uruguay and China)[343-346]. This includes a combination of behavioural support and pharmacotherapy [347, 348]. For example, in England, specialist stop smoking services, commissioned by local authorities, offer smokers face-to-face-counselling in addition to three first-line medications: NRT, bupropion or varenicline [347]. Although these have shown substantial efficacy, particularly when used in conjunction [349], calls have been made to increase their diversity [6, 350, 351].

This paper reviewed evidence for novel pharmacotherapies, contrasting them with the first-line treatments using six criteria (ESCUSE). Many of these medications are in early development and clinical trials have yet to be completed, thus conclusions of impact, efficacy and safety are limited. It does not appear that any single medication will serve as a panacea to effectively reduce smoking across the population, given that tobacco dependence reflects a complex interplay of neurobehavioral, genetic, environmental, and social factors [352].

Where evidence is available, cytisine appears to offer one of the best prospects for the future, having established safety and efficacy and being very inexpensive. Electronic cigarettes have become very popular in some countries but efficacy and long-term safety require further consideration. Nicotine vaccines and galenic formulations of varenicline could show promise if they respectively produce higher antibody levels and reduce side effects, while lorcaserin may prevent post-cessation weight gain. Several products report harm reduction benefits, including carvedilol and labetalol treatment, which are found to attenuate nicotine-induced increases in heart rate and blood pressure.

It has been argued that a major obstacle to the development of new smoking cessation and harm reduction medications is inefficient early clinical evaluations, with the vast majority of drugs failing to show efficacy for cessation after significant resources and time is wasted. This may be combated by more efficient designs (e.g. those which recruit only motivated smokers, have shorter out-come measures and use cross-over methods) [353]. Pharmaceutical companies also tend to focus research spending on the development of the next 'blockbuster drug'. Perhaps as researchers we should instead maintain focus on those products with proven safety and efficacy and assess how these can be used more widely and effectively. One way to increase effectiveness is through improved use and 
adherence, for example via free provision or reimbursement schemes [354, 355] and tackling misperceptions about smoking cessation medication [356]. Many misperceptions arise from the information provided with smoking cessation medications, which by highlighting potential risks fails to educate that these pale by comparison to the real world documented risks of tobacco use [357]. Practice guidelines for nicotine dependence also only recommend that medication be integrated with behavioural support [19], while combined use of transdermal NRT and oral NRT, varenicline and NRT, and varenicline and bupropion, appear to result in significant benefits over sole use of any product [84, 358-362]. 


\section{Compliance with Ethical Standards}

\subsection{Conflicts of interest}

RW undertakes consultancy and research for and receives travel funds and hospitality from manufacturers of smoking cessation medications but does not, and will not take funds from EC manufacturers or the tobacco industry. RW and SM are honorary co-directors of the National Centre for Smoking Cessation and Training. RW is a Trustee of the stop-smoking charity, QUIT. EB has received unrestricted funding from Pfizer. LS has undertaken honoraria and expenses for attending and presenting at meetings and workshops from manufacturers of smoking cessation products. He has also received an unrestricted research grant from Pfizer. DMC declares no conflicts of interest.

\section{Funding}

RW salary is funded by Cancer Research UK (CRUK). EB is funded by CRUK and by the National Institute for Health Research (NIHR)'s School for Public Health Research (SPHR). SM is funded by CRUK and the SPHR. The views are those of the author(s) and not necessarily those of the NHS, the NIHR or the Department of Health. SPHR is a partnership between the Universities of Sheffield; Bristol; Cambridge; Exeter; UCL; The London School for Hygiene and Tropical Medicine; the LiLaC collaboration between the Universities of Liverpool and Lancaster and Fuse; The Centre for Translational Research in Public Health, a collaboration between Newcastle, Durham, Northumbria, Sunderland and Teesside Universities. DMC is funded by Alzheimer's Research UK (ARUK). 
Table 1: Overview of first-line treatments for smoking cessation according to ESCUSE

\begin{tabular}{|c|c|c|c|c|c|c|}
\hline Drug & Efficacy & $\begin{array}{l}\text { Safety } \\
\text { Sol }\end{array}$ & cost & Use & Scope & Ease of use \\
\hline $\begin{array}{l}\text { NRT } \\
\end{array}$ & 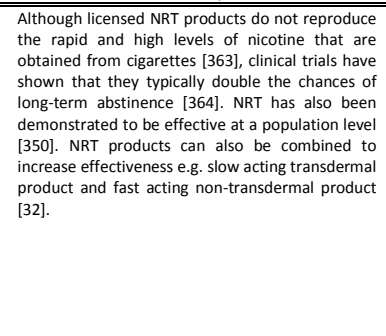 & 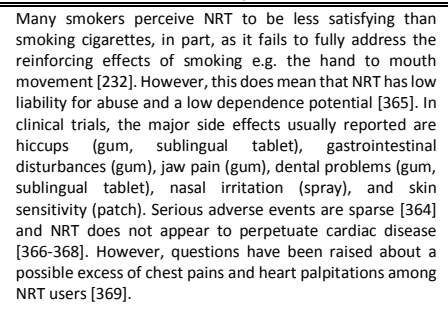 & 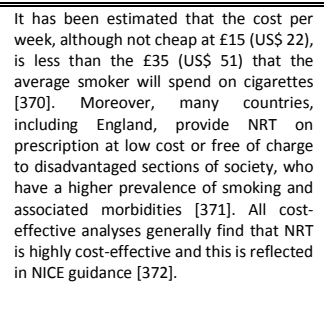 & $\begin{array}{l}\text { Prior to the advent of NRT, few } \\
\text { treatments were available to help } \\
\text { smokers stop smoking, with most } \\
\text { effort directed towards increasing } \\
\text { the public awareness of the health } \\
\text { implications of tobacco use [373]. } \\
\text { Studides suggest that the } \\
\text { introduction of novel NRT products } \\
\text { may have grown the non-tobacco } \\
\text { nicotine containing product market } \\
\text { [55]. }\end{array}$ & $\begin{array}{l}\text { NRT has a list of contraindications such as } \\
\text { heart disease, diabetes mellitus, active } \\
\text { stomach ulcer, current use of asthma or } \\
\text { depression medication, potential pregnancy } \\
\text { and condititins relevant to the specific RNT } \\
\text { product (e.s. patch: rashes or allergy to } \\
\text { adhesives) [374-376]. }\end{array}$ & 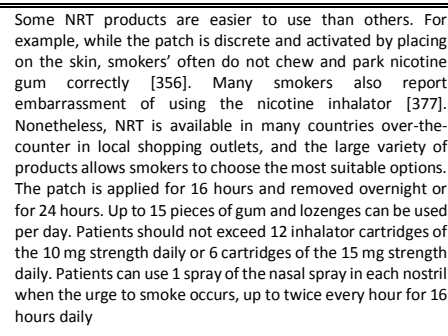 \\
\hline Bupropion & 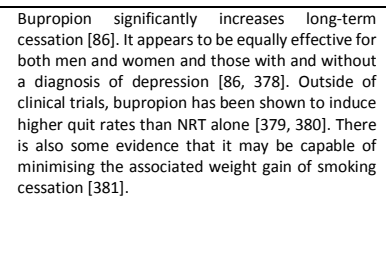 & 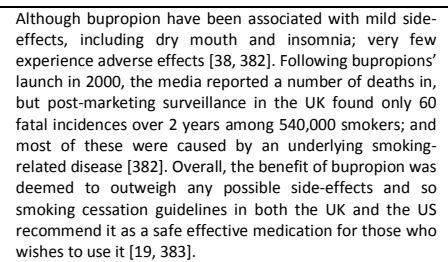 & 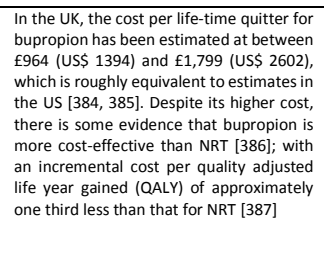 & $\begin{array}{l}\text { Prior to the introduction of } \\
\text { bupropion } \\
\text { the only } \\
\text { pharmacotherapy available to help } \\
\text { smokers quit was NRT. However, } \\
\text { despite initial promise bupropion } \\
\text { has failed to reach dominance, } \\
\text { taking less than a } 5 \% \text { share of total } \\
\text { prescribing for rmoking cessation in } \\
\text { England [388]. }\end{array}$ & 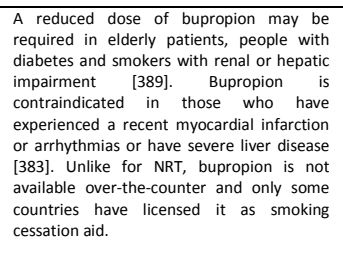 & 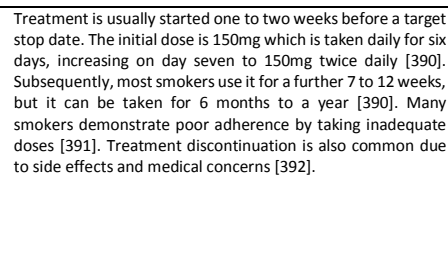 \\
\hline Varenicline & 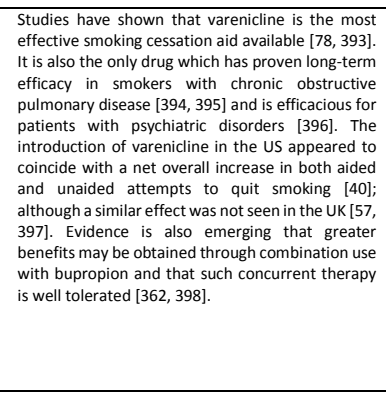 & 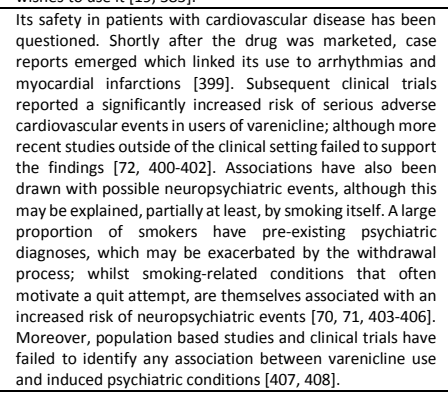 & $\begin{array}{l}\text { Varenicline has been shown to be more } \\
\text { cost-effective than either NRT or } \\
\text { burropion, though estimates vary greatly } \\
\text { due to different methodologies [409-411]. } \\
\text { The cost per additional quitter for } \\
\text { varenicline is approximately f2,170 (USS } \\
\text { 3139) [412]. }\end{array}$ & $\begin{array}{l}\text { Varenicline has become the second } \\
\text { most prescribed smoking } \\
\text { pharmacotherapy in the UK after } \\
\text { NRT [57]. However, it does not } \\
\text { appear to have increased overall } \\
\text { rates of prescribing for smoking } \\
\text { cessation medication [69]. }\end{array}$ & 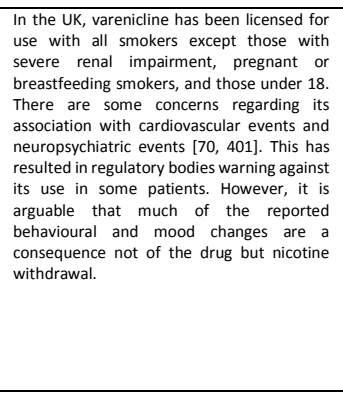 & 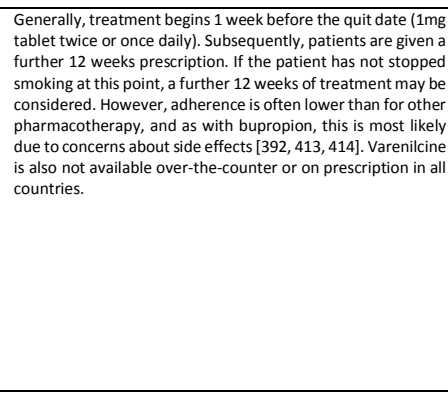 \\
\hline
\end{tabular}




\section{References}

1. Ng M, Freeman MK, Fleming TD, Robinson M, Dwyer-Lindgren $L$, Thomson B, et al. Smoking prevalence and cigarette consumption in 187 countries, 1980-2012. Jama. 2014 Jan 8;311(2):183-92.

2. World Health Organization. WHO Report on the Global Tobacco Epidemic, 2011. 2011 [cited; Available from: http://www.who.int/tobacco/global report/2011/en/

3. U.S. Department of Health and Human Services. The Health Consequences of Smoking-50 Years of Progress: A Report of the Surgeon General. 2014 [cited; Available from: http://www.cdc.gov/tobacco/data statistics/sgr/50th-anniversary/index.htm

4. Cahill K, Stevens S, Perera R, Lancaster T. Pharmacological interventions for smoking cessation: an overview and network meta-analysis. Cochrane Database Syst Rev. 2013;5(5).

5. Cahill K, Stevens S, Perera R, Lancaster T. Pharmacological interventions for smoking cessation: an overview and network meta-analysis. The Cochrane Library. 2013.

6. Kotz D, Brown J, West R. Prospective cohort study of the effectiveness of smoking cessation treatments used in the "real world". Mayo Clinic Proceedings; 2014: Elsevier; 2014. p. 1360-7.

7. Moore D, Aveyard P, Connock M, Wang D, Fry-Smith A, Barton P. Effectiveness and safety of nicotine replacement therapy assisted reduction to stop smoking: systematic review and metaanalysis. Bmj. 2009;338:b1024.

8. Beard E, McNeill A, Aveyard P, Fidler J, Michie S, West R. Use of nicotine replacement therapy for smoking reduction and during enforced temporary abstinence: a national survey of English smokers. Addiction. 2011;106.

9. Beard E, Michie S, Fidler J, West R. Use of nicotine replacement therapy in situations involving temporary abstinence from smoking: a national survey of English smokers. Addictive behaviors. 2013;38(3):1876-9.

10. West R, May S, West M, Croghan E, McEwen A. Performance of English stop smoking services in first 10 years: analysis of service monitoring data. BMJ. 2013 2013-08-20 22:31:25;347.

11. Beard E, Vangeli E, Michie S, West R. The use of nicotine replacement therapy for smoking reduction and temporary abstinence: an interview study. Nicotine \& Tobacco Research. 2012;14(7):849-56.

12. West R, Raw M, McNeill A, Stead L, Aveyard P, Bitton J, et al. Health-care interventions to promote and assist tobacco cessation: a review of efficacy, effectiveness and affordability for use in national guideline development. Addiction (Abingdon, England). 2015 07/29

$12 / 21 /$ received

03/10/revised

05/22/accepted;110(9):1388-403.

13. Ebell MH, Barry HC, Slawson DC, Shaughnessy AF. Finding POEMs in the medical literature. The Journal of family practice. 1999;48(5):350-5.

14. Singal AG, Higgins PDR, Waljee AK. A Primer on Effectiveness and Efficacy Trials. Clin Trans Gastroenterol. 2014 01/02/online;5:e45.

15. Kozlowski L, Strasser A, Giovino G, Erickson P, Terza J. Applying the risk/use equilibrium: use medicinal nicotine now for harm reduction. Tobacco Control. 2001;10(3):201.

16. Bennett $\mathrm{CL}$, Nebeker JR, Lyons EA, Samore MH, Feldman MD, McKoy JM, et al. The research on adverse drug events and reports (RADAR) project. Jama. 2005;293(17):2131-40.

17. Taylor R, Drummond M, Salkeld G, Sullivan S. Inclusion of cost effectiveness in licensing requirements of new drugs: the fourth hurdle. BMJ: British Medical Journal. 2004;329(7472):972.

18. Wang $\mathrm{F}$, Zhang $\mathrm{H}$, Zang $\mathrm{H}$, Ouyang $\mathrm{M}$. Purchasing pirated software: an initial examination of Chinese consumers. Journal of Consumer Marketing. 2005;22(6):340-51. 
19. Fiore M. Treating tobacco use and dependence; 2008 guideline. 2000.

20. Denford S, Frost J, Dieppe P, Cooper C, Britten N. Individualisation of drug treatments for patients with long-term conditions: a review of concepts. BMJ open. 2014;4(3):e004172.

21. Gligorijevic V, Malod-Dognin N, Przulj N. PATIENT-SPECIFIC DATA FUSION FOR CANCER STRATIFICATION AND PERSONALISED TREATMENT. Pac Symp Biocomput. 2016;21:321-32.

22. UK Trade and Investment. Unlock your global business potential: UK stratified medicine. 2013 [cited;

Available

from:

https://www.gov.uk/government/uploads/system/uploads/attachment data/file/301775/UK Strati fied Medicine.pdf

23. MRC. Stratified Medicine. 2016 [cited; Available from: http://www.mrc.ac.uk/research/initiatives/stratified-medicine/

24. National Collaborating Centre for Primary Care. Medicines adherence: involving patients in decisions about prescribed medicines and supporting adherence. . London, England; 2009.

25. Hu T-w, Sung H-Y, Keeler TE, Marciniak M. Cigarette consumption and sales of nicotine replacement products. Tobacco Control. 2000 June 1, 2000;9(suppl 2):ii60-ii3.

26. Russell MA. Low-tar medium-nicotine cigarettes: a new approach to safer smoking. Br Med J. 1976 Jun 12;1(6023):1430-3.

27. Russell MA, Sutton SR, Feyerabend C, Cole PV, Saloojee Y. Nicotine chewing gum as a substitute for smoking. British Medical Journal. 1977;1(6068):1060-3.

28. Jarvik ME. Beneficial effects of nicotine. British journal of addiction. 1991;86(5):571-5.

29. A report of the Surgeon General. How tobacco smoke causes disease: the biology and behavioral basis for smoking-attributable disease. 2010 [cited; Available from: http://www.surgeongeneral.gov/library/reports/

30. Difranza JR. Hooked from the first cigarette. Scientific American. 2008;298(5):82-7.

31. Bolliger $\mathrm{CT}$, van Biljon $\mathrm{X}$, Axelsson A. A nicotine mouth spray for smoking cessation: a pilot study of preference, safety and efficacy. Respiration; international review of thoracic diseases. 2007;74(2):196-201.

32. Shahab L, Brose LS, West R. Novel delivery systems for nicotine replacement therapy as an aid to smoking cessation and for harm reduction: rationale, and evidence for advantages over existing systems. CNS drugs. 2013 Dec;27(12):1007-19.

33. Shiffman S, Ferguson SG, Gwaltney CJ, Balabanis MH, Shadel WG. Reduction of abstinenceinduced withdrawal and craving using high-dose nicotine replacement therapy. Psychopharmacology. 2006 Mar; 184(3-4):637-44.

34. Shiffman S, Cone EJ, Buchhalter AR, Henningfield JE, Rohay JM, Gitchell JG, et al. Rapid absorption of nicotine from new nicotine gum formulations. Pharmacology Biochemistry and Behavior. 2009;91(3):380-4.

35. Chen LL, Inventors, inventors; United States Patent Application Publication (US 20011/0110880 A1): Nicotine Lozenege Composition 2011.

36. NICE. Smoking: harm reduction NICE guidelines [PH45]. 2013 [cited; Available from: https://www.nice.org.uk/guidance/ph45

37. Ferry LH. Non-nicotine pharmacotherapy for smoking cessation. Primary care. 1999 Sep;26(3):653-69.

38. Richmond R, Zwar N. Review of bupropion for smoking cessation. Drug and alcohol review. 2003;22(2):203-20.

39. Niaura R, Jones C, Kirkpatrick P. Varenicline. Nature reviews Drug discovery. 2006 Jul;5(7):537-

8.

40. Kasza KA, Cummings KM, Carpenter MJ, Cornelius ME, Hyland AJ, Fong GT. Use of stopsmoking medications in the United States before and after the introduction of varenicline. Addiction. 2015;110(2):346-55.

41. Cahill K, Stead L, Lancaster T. Can nicotine receptor partial agonists, including cytisine, dianicline and varenicline, help people to stop smoking? 2013. 
42. Sutherland G, Stapleton JA, Russell MA, Jarvis MJ, Hajek P, Belcher M, et al. Randomised controlled trial of nasal nicotine spray in smoking cessation. Lancet. 1992 Aug 8;340(8815):324-9.

43. Shiffman S, Ferguson SG, Rohay J, Gitchell JG. Perceived safety and efficacy of nicotine replacement therapies among US smokers and ex-smokers: relationship with use and compliance. Addiction. 2008;103(8):1371-8.

44. Kay J, Fox BS. Tolerability and pharmacokinetics of single and repeated doses of nicotine with The Straw, a novel nicotine replacement product. Nicotine \& tobacco research. 2004;6(1):63-70.

45. Thornley S, McRobbie H, Lin RB, Bullen C, Hajek P, Laugesen M, et al. A single-blind, randomized, crossover trial of the effects of a nicotine pouch on the relief of tobacco withdrawal symptoms and user satisfaction. Nicotine \& tobacco research : official journal of the Society for Research on Nicotine and Tobacco. 2009 Jun;11(6):715-21.

46. Rose JE, Turner JE, Murugesan T, Behm FM, Laugesen M. Pulmonary delivery of nicotine pyruvate: sensory and pharmacokinetic characteristics. Experimental and clinical psychopharmacology. 2010;18(5):385.

47. Paudel KS, Wu J, Hinds BJ, Stinchcomb AL. Programmable transdermal delivery of nicotine in hairless guinea pigs using carbon nanotube membrane pumps. Journal of pharmaceutical sciences. 2012;101(10):3823-32.

48. Shahab L, McEwen A, West R. Acceptability and effectiveness for withdrawal symptom relief of a novel oral nicotine delivery device: a randomised crossover trial. Psychopharmacology. 2011;216(2):187-96.

49. Pichayakorn W, Suksaeree J, Boonme P, Amnuaikit T, Taweepreda W, Ritthidej GC. Deproteinized natural rubber film forming polymeric solutions for nicotine transdermal delivery. Pharmaceutical development and technology. 2013;18(5):1111-21.

50. Shahab L, McEwen A, West R. Acceptability and effectiveness for withdrawal symptom relief of a novel oral nicotine delivery device: a randomised crossover trial. Psychopharmacology. 2011 Jul;216(2):187-96.

51. Lux J, Frecker R. Subjective responses to inhaled and intravenous injected nicotine. Clinical Pharmacology \& Therapeutics; 1988: MOSBY-YEAR BOOK INC 11830 WESTLINE INDUSTRIAL DR, ST LOUIS, MO 63146-3318; 1988. p. 186-.

52. Strasinger CL, Scheff NN, Wu J, Hinds BJ, Stinchcomb AL. Carbon nanotube membranes for use in the transdermal treatment of nicotine addiction and opioid withdrawal symptoms. Substance abuse: research and treatment. 2009;3:31.

53. Westman EC, Tomlin KF, Perkins CE, Rose JE. Oral nicotine solution for smoking cessation: a pilot tolerability study. Nicotine \& tobacco research. 2001;3(4):391-6.

54. Caldwell B, Sumner W, Crane J. A systematic review of nicotine by inhalation: is there a role for the inhaled route? Nicotine \& Tobacco Research. 2012:nts009.

55. West R, DiMarino ME, Gitchell J, McNeill A. Impact of UK policy initiatives on use of medicines to aid smoking cessation. Tob Control. 2005 Jun;14(3):166-71.

56. Beard E, Brown J, McNeill A, Michie S, West R. Has growth in electronic cigarette use by smokers been responsible for the decline in use of licensed nicotine products? Findings from the Smoking Toolkit Study: A longitudinal cross-sectional survey. Thorax. In press.

57. Kotz D, Fidler JA, West R. Did the introduction of varenicline in England substitute for or add to the use of other smoking cessation medications? Nicotine \& Tobacco Research. 2011:ntr075.

58. Henningfield JE, Slade J. Tobacco-dependence medications: public health and regulatory issues. Food \& Drug LJ. 1998;53:75.

59. Am Ende M., Roy M. C, Smith S. W, Waterman K. C, Moses S. K, Quan E.S. Pharmaceutical com- positions of 5,7,14-triazatetracyclo[10.3.1.0(2,11). 0(4,9)]-hexadeca-2(11)3,5,7,9-pentaene; 2003.

60. Waterman KC, Arikpo WB, Fergione MB, Graul TW, Johnson BA, MacDonald BC, et al. Nmethylation and $\mathrm{N}$-formylation of a secondary amine drug (varenicline) in an osmotic tablet. Journal of Pharmaceutical Sciences. 2008;97(4):1499-507. 
61. Johnson BA, Ziegler CB. Transdermal system for varenicline. Google Patents; 2011.

62. Mansour HM, Sohn M, Al-Ghananeem A, Deluca PP. Materials for pharmaceutical dosage forms: molecular pharmaceutics and controlled release drug delivery aspects. International journal of molecular sciences. 2010;11(9):3298-322.

63. Kumar VS, Niranjan SK, Irchhaiya R, Neeraj K, Ali A. A noevel transdermal drug delivery system. International Research Journal of Pharmacy. 2012;3(8):39-44.

64. George O, Lloyd A, Carroll FI, Damaj MI, Koob GF. Varenicline blocks nicotine intake in rats with extended access to nicotine self-administration. Psychopharmacology. 2011 10/06;213(4):71522.

65. DeVane CL. Immediate-release versus controlled-release formulations: pharmacokinetics of newer antidepressants in relation to nausea. The Journal of clinical psychiatry. 2003;64 Suppl 18:149.

66. Sedlacek H-H, Sapienza AM, Eid V. Ways to successful strategies in drug research and development: John Wiley \& Sons; 2008.

67. Stapleton J. Is varenicline cost-effective enough to be funded by the NHS now? . 2006 [cited; Available from: http://www.ash.org.uk/files/documents/ASH 446.pdf

68. Kasza KA, Cummings KM, Carpenter MJ, Cornelius ME, Hyland AJ, Fong GT. Use of stopsmoking medications in the United States before and after the introduction of varenicline. Addiction. 2015 Feb;110(2):346-55.

69. Langley TE, Huang Y, McNeill A, Coleman T, Szatkowski L, Lewis S. Prescribing of smoking cessation medication in England since the introduction of varenicline. Addiction. $2011 \mathrm{Jul} ; 106(7): 1319-$ 24.

70. Meyer TE, Taylor LG, Xie S, Graham DJ, Mosholder AD, Williams JR, et al. Neuropsychiatric events in varenicline and nicotine replacement patch users in the Military Health System. Addiction. 2013;108(1):203-10.

71. Pasternak B, Svanström $\mathrm{H}$, Hviid A. Use of varenicline versus bupropion and risk of psychiatric adverse events. Addiction. 2013;108(7):1336-43.

72. Prochaska JJ, Hilton JF. Risk of cardiovascular serious adverse events associated with varenicline use for tobacco cessation: systematic review and meta-analysis. Bmj. 2012;344.

73. Jeong SH, Newcombe D, Sheridan J, Tingle M. Pharmacokinetics of cytisine, an $\alpha 4 \beta 2$ nicotinic receptor partial agonist, in healthy smokers following a single dose. Drug Testing and Analysis. 2014:n/a-n/a.

74. Barlow RB, McLeod LJ. Some studies on cytisine and its methylated derivatives. British journal of pharmacology. 1969 Jan;35(1):161-74.

75. Reavill C, Walther B, Stolerman IP, Testa B. Behavioural and pharmacokinetic studies on nicotine, cytisine and lobeline. Neuropharmacology. 1990 Jul;29(7):619-24.

76. Etter JF. Cytisine for smoking cessation: a literature review and a meta-analysis. Arch Intern Med. 2006 Aug 14-28;166(15):1553-9.

77. Hajek $\mathrm{P}, \mathrm{McRobbie} H$, Myers K. Efficacy of cytisine in helping smokers quit: systematic review and meta-analysis. Thorax. 2013;68(11):1037-42.

78. Cahill K, Stead LF, Lancaster T. Nicotine receptor partial agonists for smoking cessation. Cochrane Database Syst Rev. 2012;4:Cd006103.

79. Walker N, Howe C, Glover M, McRobbie H, Barnes J, Nosa V, et al. Cytisine versus nicotine for smoking cessation. N Engl J Med. 2014 Dec 18;371(25):2353-62.

80. Leaviss J, Sullivan W, Ren S, Everson-Hock E, Stevenson M, Stevens JW, et al. What is the clinical effectiveness and cost-effectiveness of cytisine compared with varenicline for smoking cessation? A systematic review and economic evaluation. Health Technol Assess. 2014 May;18(33):1120.

81. Samet JM. Cytisine is effective for smoking cessation: should clinicians use it? Evidence Based Medicine. 2014 February 18, 2014. 
82. West R, DiMarino M, Gitchell J, McNeill A. Impact of UK policy initiatives on use of medicines to aid smoking cessation. Tobacco Control. 2005;14(3):166-71.

83. Filippidis FT, Gerovasili V, Vardavas Cl, Agaku IT, Tountas Y. Determinants of use of smoking cessation aids in 27 European countries. Preventive medicine. 2014;65:99-102.

84. Koegelenberg CF, Noor F, Bateman ED, van Zyl-Smit RN, Bruning A, O'Brien JA, et al. Efficacy of varenicline combined with nicotine replacement therapy vs varenicline alone for smoking cessation: a randomized clinical trial. Jama. 2014;312(2):155-61.

85. Jiloha RC. Pharmacotherapy of smoking cessation. Indian Journal of Psychiatry. 2014 JanMar;56(1):87-95.

86. Hughes JR, Stead LF, Hartmann-Boyce J, Cahill K, Lancaster T. Antidepressants for smoking cessation. Cochrane Database Syst Rev. 2014;1:CD000031.

87. Hughes JR, Stead LF, Lancaster T. Nortriptyline for smoking cessation: a review. Nicotine \& tobacco research : official journal of the Society for Research on Nicotine and Tobacco. 2005 Aug;7(4):491-9.

88. Aveyard P, Johnson C, Fillingham S, Parsons A, Murphy M. Nortriptyline plus nicotine replacement versus placebo plus nicotine replacement for smoking cessation: pragmatic randomised controlled trial. BMJ. 2008 2008-05-29 22:01:31;336(7655):1223-7.

89. Wagena EJ, Knipschild P, Zeegers MP. Should nortriptyline be used as a first-line aid to help smokers quit? Results from a systematic review and meta-analysis. Addiction. 2005 Mar;100(3):31726.

90. Hall SM, Lightwood JM, Humfleet GL, Bostrom A, Reus VI, Munoz R. Cost-effectiveness of bupropion, nortriptyline, and psychological intervention in smoking cessation. J Behav Health Serv Res. 2005 Oct-Dec;32(4):381-92.

91. McRobbie H, Bullen C, Glover M, Whittaker R, Wallace-Bell M, Fraser T. New Zealand smoking cessation guidelines. The New Zealand Medical Journal (Online). 2008;121(1276).

92. Dawkins L. Electronic cigarettes: what are they and are they effective? E-Cigarette Summit, London, UK: (oral presentation). 2013 [cited; Available from: http://e-cigarette-summit.com/wpcontent/uploads/2013/12/Summit-Presentations.pdf

93. Torjesen I. E-cigarettes are to be regulated as medicines from 2016. Bmj. 2013;346.

94. MHRA. Nicotine containing products. 2013 [cited; Available from: www.mhra.gov.uk/Safetyinformation/Generalsafetyinformationandadvice/Product-

specificinformationandadvice/Product-specificinformationandadvice-M-

T/Nicotinecontainingproducts/index.htm.

95. MHRA. UKPAR e-Voke 10 \& 15mg Electronic Inhaler 2015 [cited; Available from: http://www.mhra.gov.uk/home/groups/par/documents/websiteresources/con616843.pdf

96. McRobbie H, Bullen C, Hartmann-Boyce J, Hajek P. Electronic cigarettes for smoking cessation and reduction. The Cochrane Library. 2014.

97. Brown J, Beard E, Kotz D, Michie S, West R. Real-world effectiveness of e-cigarettes when used to aid smoking cessation: a cross-sectional population study. Addiction. 2014;109(9):1531-40.

98. Adkison SE, O'Connor RJ, Bansal-Travers M, Hyland A, Borland R, Yong $\mathrm{H}-\mathrm{H}$, et al. Electronic nicotine delivery systems: international tobacco control four-country survey. American journal of preventive medicine. 2013;44(3):207-15.

99. Etter J-F, Bullen C. A longitudinal study of electronic cigarette users. Addictive behaviors. 2014;39(2):491-4.

100. Brose LS, Hitchman SC, Brown J, West R, McNeill A. Is use of electronic cigarettes while smoking associated with smoking cessation attempts, cessation and reduced cigarette consumption? A survey with a 1-year follow-up. Addiction. 2015:n/a-n/a.

101. Hecht SS. Cigarette smoking and lung cancer: chemical mechanisms and approaches to prevention. The lancet oncology. 2002;3(8):461-9.

102. Westenberger B. Evaluation of e-cigarettes. St Louis, MO: Food and Drug Administration. 2009:1-8. 
103. Hadwiger ME, Trehy ML, Ye W, Moore T, Allgire J, Westenberger B. Identification of aminotadalafil and rimonabant in electronic cigarette products using high pressure liquid chromatography with diode array and tandem mass spectrometric detection. Journal of chromatography A. 2010;1217(48):7547-55.

104. Goniewicz ML, Knysak J, Gawron M, Kosmider L, Sobczak A, Kurek J, et al. Levels of selected carcinogens and toxicants in vapour from electronic cigarettes. Tobacco control. 2014;23(2):133-9.

105. Williams M, Villarreal A, Bozhilov K, Lin S, Talbot P. Metal and silicate particles including nanoparticles are present in electronic cigarette cartomizer fluid and aerosol. PloS one. 2013;8(3):e57987.

106. Farsalinos KE, Polosa R. Safety evaluation and risk assessment of electronic cigarettes as tobacco cigarette substitutes: a systematic review. Therapeutic Advances in Drug Safety. 2014;5(2):6786.

107. Hajek P, Etter J-F, Benowitz N, Eissenberg T, McRobbie H. Electronic cigarettes: review of use, content, safety, effects on smokers and potential for harm and benefit. Addiction. 2014;109(11):180110.

108. McNeill A, Brose L, Calder R, Hitchman S, Hajek P, McRobbie H. E-cigarettes: an evidence update. A report commissioned by Public Health England. Public Health England $<$ www gov uk/government/uploads/system/uploads/attachment_data/file/454516/Ecigarettes_an_evidence_u pdate_A_report_commissioned_by_Public_Health_England pdf $>$ (Accessed August 22, 2015). 2015.

109. NHS Choices. News analysis: E-cigarettes to be regulated as medicines 2013.

110. NCSCT. Electronic cigarettes: A briefing for stop smoking services. 2016 [cited; Available from: http://www.ncsct.co.uk/usr/pub/Electronic\%20cigarettes.\%20A\%20briefing\%20for\%20stop\%20smo king\%20services.pdf

111. Bullen C, Howe C, Laugesen M, McRobbie H, Parag V, Williman J, et al. Electronic cigarettes for smoking cessation: a randomised controlled trial. The Lancet. 2013;382(9905):1629-37.

112. Hughes JR, Stead LF, Lancaster T. Anxiolytics for smoking cessation. The Cochrane Library. 2000.

113. Glassman AH, Stetner F, Walsh BT, Raizman PS, Fleiss JL, Cooper TB, et al. Heavy smokers, smoking cessation, and clonidine. Results of a double-blind, randomized trial. Jama. 1988 May 20;259(19):2863-6.

114. Prochazka AV, Petty TL, Nett L, et al. TRansdermal clonidine reduced some withdrawal symptoms but did not increase smoking cessation. Archives of Internal Medicine. 1992;152(10):20659.

115. Fiore MC, Bailey WC, Cohen SJ, Dorfman SF, Goldstein MG, Gritz ER, et al. Treating tobacco use and dependence: a clinical practice guideline: Publications Clearinghouse; 2000.

116. Gourlay SG, Stead LF, Benowitz NL. Clonidine for smoking cessation. Cochrane Database Syst Rev. 2004(3):Cd000058.

117. Ornish SA, Zisook S, McAdams L. Effects of transdermal clonidine treatment on withdrawal symptoms associated with smoking cessation: A randomized, controlled trial. Archives of Internal Medicine. 1988;148(9):2027-31.

118. Franks P, Harp J, Bell B. RAndomized, controlled trial of clonidine for smoking cessation in a primary care setting. Jama. 1989;262(21):3011-3.

119. Hughes JR, Gust SW, Skoog K, Keenan RM, Fenwick JW. Symptoms of tobacco withdrawal. A replication and extension. Arch Gen Psychiatry. 1991 Jan;48(1):52-9.

120. Charles J Bentz. Review: clonidine is more effective than placebo for long term smoking cessation, but has side effects. Evidence Based Medicine. 2005 February 1, 2005;10(1):19.

121. American Cancer Society. Prescription drugs to help you quit smoking. 2014.

122. Luger TM, Suls J, Vander Weg MW. How robust is the association between smoking and depression in adults? A meta-analysis using linear mixed-effects models. Addictive behaviors. 2014;39(10):1418-29. 
123. Nowakowska E, Kus K, Florek E, Czubak A, Jodynis-Liebert J. The influence of tobacco smoke and nicotine on antidepressant and memory-improving effects of venlafaxine. Hum Exp Toxicol. 2006 Apr;25(4):199-209.

124. Cinciripini PM, Tsoh JY, Wetter DW, Lam C, de Moor C, Cinciripini L, et al. Combined effects of venlafaxine, nicotine replacement, and brief counseling on smoking cessation. Experimental and clinical psychopharmacology. 2005;13(4):282.

125. Bet PM, Hugtenburg JG, Penninx BW, Hoogendijk WJ. Side effects of antidepressants during long-term use in a naturalistic setting. European neuropsychopharmacology. 2013;23(11):1443-51.

126. Thase ME, Clayton AH, Haight BR, Thompson AH, Modell JG, Johnston JA. A double-blind comparison between bupropion $\mathrm{XL}$ and venlafaxine $\mathrm{XR}$ : sexual functioning, antidepressant efficacy, and tolerability. J Clin Psychopharmacol. 2006 Oct;26(5):482-8.

127. Masand PS, Gupta S. Long-Term Side Effects of Newer-Generation Antidepressants: SSRIS, Venlafaxine, Nefazodone, Bupropion, and Mirtazapine. Annals of Clinical Psychiatry. 2002;14(3):17582.

128. Khalifa M, Daleau P, Drolet B. Turseon. Block of sodium channels underlies unheraldded cardiac toxicity observed with the antidepressant agent venlafaxine. J Mol Cell Cardiol. 1998;30:A136. 129. Lenox-Smith A, Greenstreet L, Burslem K, Knight C. Cost effectiveness of venlafaxine compared with generic fluoxetine or generic amitriptyline in major depressive disorder in the UK. Clin Drug Investig. 2009;29(3):173-84.

130. Holliday SM, Benfield P. Venlafaxine. Drugs. 1995;49(2):280-94.

131. Schuller HM, Jull BA, Sheppard BJ, Plummer HK. Interaction of tobacco-specific toxicants with the neuronal $\alpha 7$ nicotinic acetylcholine receptor and its associated mitogenic signal transduction pathway: potential role in lung carcinogenesis and pediatric lung disorders. European journal of pharmacology. 2000;393(1):265-77.

132. Stead L, Hughes J. Can lobeline help people to quit smoking. Health. 2012.

133. Kitagawa H, Takenouchi T, Azuma R, Wesnes KA, Kramer WG, Clody DE, et al. Safety, pharmacokinetics, and effects on cognitive function of multiple doses of GTS-21 in healthy, male volunteers. Neuropsychopharmacology: official publication of the American College of Neuropsychopharmacology. 2003;28(3):542-51.

134. Johnstone TB, Hogenkamp DJ, Coyne L, Su J, Halliwell RF, Tran MB, et al. Modifying quinolone antibiotics yields new anxiolytics. Nat Med. 2004 Jan;10(1):31-2.

135. Crooks PA, Bardo MT, Dwoskin LP. Nicotinic Receptor Antagonists as Treatments for Nicotine Abuse. Advances in pharmacology (San Diego, Calif). 2014;69:513-51.

136. Shytle R, Penny E, Silver A, Goldman J, Sanberg P. Mecamylamine (Inversine ${ }^{\circledR}$ ): an old antihypertensive with new research directions. Journal of human hypertension. 2002;16(7):453-7.

137. Rose J, Behm F, Westman E. Brand-switching and gender effects in mecamylamine/nicotine smoking cessation treatment. Nicotine Tobacco Res. 1999;1:286-7.

138. Leonard S, Adams CE. Smoking cessation and schizophrenia. The American journal of psychiatry. 2006;163(11):1877.

139. Freedman R, Olincy A, Buchanan RW, Harris JG, Gold JM, Johnson L, et al. Initial phase 2 trial of a nicotinic agonist in schizophrenia. The American journal of psychiatry. 2008 Aug;165(8):1040-7.

140. Tuan EW, Horti AG, Olson TT, Gao Y, Stockmeier CA, Al-Muhtasib N, et al. AT-1001 Is a Partial Agonist with High Affinity and Selectivity at Human and Rat alpha3beta4 Nicotinic Cholinergic Receptors. Mol Pharmacol. 2015 Oct;88(4):640-9.

141. Yoshimura RF, Hogenkamp DJ, Li WY, Tran MB, Belluzzi JD, Whittemore ER, et al. Negative allosteric modulation of nicotinic acetylcholine receptors blocks nicotine self-administration in rats. J Pharmacol Exp Ther. 2007 Dec;323(3):907-15.

142. Rose JE, Behm FM, Westman EC, Levin ED, Stein RM, Ripka GV. Mecamylamine combined with nicotine skin patch facilitates smoking cessation beyond nicotine patch treatment alone. Clinical pharmacology and therapeutics. 1994 Jul;56(1):86-99. 
143. Lancaster T, Stead LF. Mecamylamine (a nicotine antagonist) for smoking cessation. The Cochrane Library. 1998.

144. Cucchiaro G, Xiao Y, Gonzalez-Sulser A, Kellar KJ. Analgesic effects of Sazetidine-A, a new nicotinic cholinergic drug. Anesthesiology. 2008 Sep;109(3):512-9.

145. Smith RC, Singh A, Infante M, Khandat A, Kloos A. Effects of cigarette smoking and nicotine nasal spray on psychiatric symptoms and cognition in schizophrenia. Neuropsychopharmacology : official publication of the American College of Neuropsychopharmacology. 2002;27(3):479-97.

146. West R. Glucose for smoking cessation. CNS drugs. 2001;15(4):261-5.

147. West R, May S, McEwen A, McRobbie H, Hajek P, Vangeli E. A randomised trial of glucose tablets to aid smoking cessation. Psychopharmacology. 2010 Jan;207(4):631-5.

148. McRobbie H, Hajek P. Effect of glucose on tobacco withdrawal symptoms in recent quitters using bupropion or nicotine replacement. Human psychopharmacology. 2004 Jan;19(1):57-61.

149. Henningfield JE, Keenan RM. Nicotine delivery kinetics and abuse liability. J Consult Clin Psychol. 1993 Oct;61(5):743-50.

150. Pentel PR, LeSage MG. New Directions in Nicotine Vaccine Design and Use. Advances in pharmacology (San Diego, Calif). 2014;69:553-80.

151. Pravetoni M, Keyler DE, Pidaparthi RR, Carroll FI, Runyon SP, Murtaugh MP, et al. Structurally distinct nicotine immunogens elicit antibodies with non-overlapping specificities. Biochemical pharmacology. 2012 Feb 15;83(4):543-50.

152. de Villiers SH, Cornish KE, Troska AJ, Pravetoni M, Pentel PR. Increased efficacy of a trivalent nicotine vaccine compared to a dose-matched monovalent vaccine when formulated with alum. Vaccine. 2013 Dec 16;31(52):6185-93.

153. LeSage MG, Shelley D, Pravetoni M, Pentel PR. Enhanced attenuation of nicotine discrimination in rats by combining nicotine-specific antibodies with a nicotinic receptor antagonist. Pharmacology, biochemistry, and behavior. 2012 Jul;102(1):157-62.

154. Selecta Biosciences. Recent news. Selecta Biosciences Initiates Phase 1 Clinical Study of SEL068, a First-in-Class Synthetic Nicotine Vaccine for Smoking Cessation and Relapse Prevention. 2011 [cited; Available from: http://www.selectabio.com/news/recent-news/Selecta-Biosciences-InitiatesPhase-1-Clinical-Study-of-SEL-068.cfm

155. Brimijoin S, Shen $\mathrm{X}$, Orson F, Kosten T. Prospects, promise and problems on the road to effective vaccines and related therapies for substance abuse. Expert review of vaccines. 2013 Mar;12(3):323-32.

156. Cerny EH, Levy R, Mauel J, Mpandi M, Mutter M, Henzelin-Nkubana C, et al. Preclinical development of a vaccine 'against smoking'. Onkologie. 2002 Oct;25(5):406-11.

157. Maurer $P$, Jennings GT, Willers J, Rohner F, Lindman $Y$, Roubicek K, et al. A therapeutic vaccine for nicotine dependence: preclinical efficacy, and Phase I safety and immunogenicity. European journal of immunology. $2005 \mathrm{Jul} ; 35(7): 2031-40$.

158. Pravetoni M, Keyler DE, Raleigh MD, Harris AC, Lesage MG, Mattson CK, et al. Vaccination against nicotine alters the distribution of nicotine delivered via cigarette smoke inhalation to rats. Biochemical pharmacology. 2011 May 1;81(9):1164-70.

159. Satoskar SD, Keyler DE, LeSage MG, Raphael DE, Ross CA, Pentel PR. Tissue-dependent effects of immunization with a nicotine conjugate vaccine on the distribution of nicotine in rats. International immunopharmacology. $2003 \mathrm{Jul} ; 3(7): 957-70$.

160. LeSage MG, Keyler DE, Hieda Y, Collins G, Burroughs D, Le C, et al. Effects of a nicotine conjugate vaccine on the acquisition and maintenance of nicotine self-administration in rats. Psychopharmacology. 2006 Mar;184(3-4):409-16.

161. Lindblom N, de Villiers SH, Kalayanov G, Gordon S, Johansson AM, Svensson TH. Active immunization against nicotine prevents reinstatement of nicotine-seeking behavior in rats. Respiration; international review of thoracic diseases. 2002;69(3):254-60.

162. Fahim RE, Kessler PD, Kalnik MW. Therapeutic vaccines against tobacco addiction. Expert review of vaccines. 2013 Mar;12(3):333-42. 
163. Hatsukami DK, Jorenby DE, Gonzales D, Rigotti NA, Glover ED, Oncken CA, et al. Immunogenicity and smoking-cessation outcomes for a novel nicotine immunotherapeutic. Clinical pharmacology and therapeutics. 2011 Mar;89(3):392-9.

164. Tonstad S, Heggen E, Giljam H, Lagerback PA, Tonnesen P, Wikingsson LD, et al. Niccine(R), a nicotine vaccine, for relapse prevention: a phase II, randomized, placebo-controlled, multicenter clinical trial. Nicotine \& tobacco research : official journal of the Society for Research on Nicotine and Tobacco. 2013 Sep;15(9):1492-501.

165. Cornuz J, Zwahlen S, Jungi WF, Osterwalder J, Klingler K, van Melle G, et al. A vaccine against nicotine for smoking cessation: a randomized controlled trial. PloS one. 2008;3(6):e2547.

166. Lockner JW, Lively JM, Collins KC, Vendruscolo JC, Azar MR, Janda KD. A conjugate vaccine using enantiopure hapten imparts superior nicotine-binding capacity. J Med Chem. 2015 Jan 22;58(2):1005-11.

167. Hoogsteder PH, Kotz D, van Spiegel PI, Viechtbauer W, van Schayck OC. Efficacy of the nicotine vaccine 3'-AmNic-rEPA (NicVAX) co-administered with varenicline and counselling for smoking cessation: a randomized placebo-controlled trial. Addiction. 2014 Aug;109(8):1252-9.

168. Pittet L, Altreuter D, Ilyinskii P, Fraser C, Gao Y, Baldwin S, et al. Development and preclinical evaluation of SEL-068, a novel targeted Synthetic Vaccine Particle (tSVP' ${ }^{\mathrm{TM}}$ ) for smoking cessation and relapse prevention that generates high titers of antibodies against nicotine. The Journal of Immunology. 2012;188(Meeting Abstracts 1):75.11.

169. Desai RI, Bergman J. Effects of the Nanoparticle-based Vaccine, SEL-068, on Nicotine Discrimination in Squirrel Monkeys. Neuropsychopharmacology : official publication of the American College of Neuropsychopharmacology. 2015 Mar 6.

170. Hatsukami DK, Rennard S, Jorenby D, Fiore M, Koopmeiners J, Vos A, et al. Safety and immunogenicity of a nicotine conjugate vaccine in current smokers. Clinical Pharmacology \& Therapeutics. 2005;78(5):456-67.

171. Gartner CE, Barendregt JJ, Wallace A, Hall WD. Would vaccination against nicotine be a costeffective way to prevent smoking uptake in adolescents? Addiction. 2012 Apr;107(4):801-9.

172. Shen $X$, Orson FM, Kosten TR. Vaccines against drug abuse. Clinical Pharmacology \& Therapeutics. 2012;91(1):60-70.

173. Raupach T, Hoogsteder PH, Onno van Schayck CP. Nicotine vaccines to assist with smoking cessation: current status of research. Drugs. 2012 Mar 5;72(4):e1-16.

174. Hammond D, Reid JL, Driezen P, Cummings KM, Borland R, Fong GT, et al. Smokers' use of nicotine replacement therapy for reasons other than stopping smoking: findings from the ITC Four Country Survey. Addiction. 2008;103(10):1696-703.

175. Buchhalter AR, Fant RV, Henningfield JE. Novel pharmacological approaches for treating tobacco dependence and withdrawal: current status. Drugs. 2008;68(8):1067-88.

176. Jackson A, Nesic J, Groombridge C, Clowry O, Rusted J, Duka T. Differential involvement of glutamatergic mechanisms in the cognitive and subjective effects of smoking. Neuropsychopharmacology : official publication of the American College of Neuropsychopharmacology. 2009;34(2):257-65.

177. Zona C, Ciotti MT, Avoli M. Topiramate attenuates voltage-gated sodium currents in rat cerebellar granule cells. Neurosci Lett. 1997 Aug 15;231(3):123-6.

178. Shinn AK, Greenfield SF. Topiramate in the treatment of substance related disorders: a critical review of the literature. The Journal of clinical psychiatry. 2010;71(5):634.

179. Simeone TA, Wilcox KS, White HS. Subunit selectivity of topiramate modulation of heteromeric GABAA receptors. Neuropharmacology. 2006 6//;50(7):845-57.

180. McElroy SL, Hudson JI, Capece JA, Beyers K, Fisher AC, Rosenthal NR. Topiramate for the treatment of binge eating disorder associated with obesity: a placebo-controlled study. Biological psychiatry. 2007 May 1;61(9):1039-48. 
181. Paparrigopoulos T, Tzavellas E, Karaiskos D, Kourlaba G, Liappas I. Treatment of alcohol dependence with low-dose topiramate: an open-label controlled study. BMC psychiatry. 2011;11(1):41.

182. Dunn KE, Marcus TF, Kim C, Schroeder JR, Vandrey R, Umbricht A. Zonisamide Reduces Withdrawal Symptoms But Does Not Enhance Varenicline-Induced Smoking Cessation. Nicotine \& Tobacco Research. 2015 October 17, 2015.

183. Kukkar A, Bali A, Singh N, Jaggi AS. Implications and mechanism of action of gabapentin in neuropathic pain. Arch Pharm Res. 2013 Mar;36(3):237-51.

184. Parker DAS, Ong J, Marino V, Kerr DIB. Gabapentin activates presynaptic GABAB heteroreceptors in rat cortical slices. European Journal of Pharmacology. 2004 7/14/;495(2-3):13743.

185. Sofuoglu M, Mouratidis M, Yoo S, Culligan K, Kosten T. Effects of tiagabine in combination with intravenous nicotine in overnight abstinent smokers. Psychopharmacology. 2005 Sep;181(3):504-10.

186. Eckstein-Ludwig U, Fei J, Schwarz W. Inhibition of uptake, steady-state currents, and transient charge movements generated by the neuronal GABA transporter by various anticonvulsant drugs. British journal of pharmacology. 1999 Sep;128(1):92-102.

187. Romberger DJ, Grant K. Alcohol consumption and smoking status: the role of smoking cessation. Biomedicine \& Pharmacotherapy. 2004;58(2):77-83.

188. Grant BF, Hasin DS, Chou SP, Stinson FS, Dawson DA. Nicotine dependence and psychiatric disorders in the united states: Results from the national epidemiologic survey on alcohol and relatedconditions. Archives of general psychiatry. 2004;61(11):1107-15.

189. Baltieri DA, Daró FR, Ribeiro PL, de Andrade AG. Effects of topiramate or naltrexone on tobacco use among male alcohol-dependent outpatients. Drug and alcohol dependence. 2009;105(1):33-41.

190. Johnson BA, Ait-Daoud N, Akhtar FZ, Javors MA. Use of oral topiramate to promote smoking abstinence among alcohol-dependent smokers: a randomized controlled trial. Archives of Internal Medicine. 2005;165(14):1600-5.

191. Anthenelli RM, Blom TJ, McElroy SL, Keck PE. Preliminary evidence for gender-specific effects of topiramate as a potential aid to smoking cessation. Addiction. 2008;103(4):687-94.

192. Holes-Lewis KA, Malcolm R, O'Neil PM. Pharmacotherapy of obesity: clinical treatments and considerations. The American journal of the medical sciences. 2013;345(4):284-8.

193. Oncken C, Arias AJ, Feinn R, Litt M, Covault J, Sofuoglu M, et al. Topiramate for Smoking Cessation: A Randomized, Placebo-Controlled Pilot Study. Nicotine \& Tobacco Research. 2014 March 1, 2014;16(3):288-96.

194. Addolorato G, Caputo F, Capristo E, Colombo G, Gessa GL, Gasbarrini G. Ability of baclofen in reducing alcohol craving and intake: II-preliminary clinical evidence. Alcoholism: Clinical and Experimental Research. 2000;24(1):67-71.

195. Franklin TR, Harper D, Kampman K, Kildea-McCrea S, Jens W, Lynch KG, et al. The GABA B agonist baclofen reduces cigarette consumption in a preliminary double-blind placebo-controlled smoking reduction study. Drug and alcohol dependence. 2009;103(1):30-6.

196. Leggio L, Zywiak WH, Edwards SM, Tidey JW, Swift RM, Kenna GA. A preliminary double-blind, placebo-controlled randomized study of baclofen effects in alcoholic smokers. Psychopharmacology. 2015;232(1):233-43.

197. Myrick H, Malcolm R, Henderson S, McCormick K. Gabapentin for misuse of homemade nicotine nasal spray. The American journal of psychiatry. 2001 Mar;158(3):498.

198. White WD, Crockford D, el-Guebaly N, Patten S. A randomized, open-label pilot comparison of gabapentin and bupropion SR for smoking cessation. Nicotine \& tobacco research. 2005;7(5):80913.

199. Sood A, Ebbert JO, Schroeder DR, Croghan IT, Sood R, Vander Weg MW, et al. Gabapentin for smoking cessation: a preliminary investigation of efficacy. Nicotine \& tobacco research : official journal of the Society for Research on Nicotine and Tobacco. 2007 Feb;9(2):291-8. 
200. Sood A, Ebbert JO, Wyatt KD, Croghan IT, Schroeder DR, Sood R, et al. Gabapentin for smoking cessation. Nicotine \& Tobacco Research. 2010 01/15

08/11/received

11/25/accepted;12(3):300-4.

201. Licata SC, Rowlett JK. Abuse and dependence liability of benzodiazepine-type drugs: GABA A receptor modulation and beyond. Pharmacology Biochemistry and Behavior. 2008;90(1):74-89.

202. Khazaal Y, Cornuz J, Bilancioni R, Zullino DF. Topiramate for smoking cessation. Psychiatry and Clinical Neurosciences. 2006;60(3):384-8.

203. Verrotti A, Loiacono G, Di Sabatino F, Zaccara G. The adverse event profile of zonisamide: a meta-analysis. Acta Neurol Scand. 2013 Nov;128(5):297-304.

204. Mula M. Topiramate and cognitive impairment: evidence and clinical implications. Therapeutic Advances in Drug Safety. 2012;3(6):279-89.

205. Kuehn BM. FDA warns of adverse events linked to smoking cessation drug and antiepileptics. Jama. 2008;299(10):1121-2.

206. NHS Cumbria Medicines Management Team. Pregablin or Gabapentin for neuropathic pain? 2012 [cited; Available from: http://www.cumbria.nhs.uk/ProfessionalZone/MedicinesManagement/Guidelines/Pregablin-forneuropathic-pain.pdf

207. Brown JS, Papadopoulos G, Neumann PJ, Price M, Friedman M, Menzin J. Cost-effectiveness of migraine prevention: the case of topiramate in the UK. Cephalalgia. 2006 Dec;26(12):1473-82.

208. Evins AE, Pachas G, Mischoulon D, Urbanoski K, Carlini S, Sousa J, et al. A double-blind, placebo-controlled trial of the NMDA glycine site antagonist, GW468816, for prevention of relapse to smoking in females. J Clin Psychopharmacol. 2011 Oct;31(5):597-602.

209. Hara K, Sata T. Inhibitory effect of gabapentin on N-methyl-d-aspartate receptors expressed in Xenopus oocytes. Acta anaesthesiologica scandinavica. 2007;51(1):122-8.

210. Kim Y-S, Chang H-K, Lee J-W, Sung Y-H, Kim S-E, Shin M-S, et al. Protective effect of gabapentin on $\mathrm{N}$-methyl-D-aspartate-induced excitotoxicity in rat hippocampal CA1 neurons. Journal of pharmacological sciences. 2009;109(1):144-7.

211. Yeh C-Y, Chung S-C, Tseng F-L, Tsai Y-C, Liu Y-C. Biphasic effects of chronic intrathecal gabapentin administration on the expression of protein kinase $C$ gamma in the spinal cord of neuropathic pain rats. Acta Anaesthesiologica Taiwanica. 2011;49(4):144-8.

212. Schmaal L, Berk L, Hulstijn KP, Cousijn J, Wiers RW, van Den Brink W. Efficacy of Nacetylcysteine in the treatment of nicotine dependence: a double-blind placebo-controlled pilot study. European addiction research. 2011(17):211-6.

213. Baker DA, Xi ZX, Shen H, Swanson CJ, Kalivas PW. The origin and neuronal function of in vivo nonsynaptic glutamate. J Neurosci. 2002 Oct 15;22(20):9134-41.

214. Moran MM, McFarland K, Melendez RI, Kalivas PW, Seamans JK. Cystine/glutamate exchange regulates metabotropic glutamate receptor presynaptic inhibition of excitatory transmission and vulnerability to cocaine seeking. J Neurosci. 2005 Jul 6;25(27):6389-93.

215. Varga V, Jenei Z, Janaky R, Saransaari P, Oja SS. Glutathione is an endogenous ligand of rat brain N-methyl-D-aspartate (NMDA) and 2-amino-3-hydroxy-5-methyl-4-isoxazolepropionate (AMPA) receptors. Neurochem Res. 1997 Sep;22(9):1165-71.

216. Ogita K, Kitago T, Nakamuta $H$, Fukuda $Y$, Koida $M$, Ogawa $Y$, et al. Glutathione-induced inhibition of $\mathrm{Na}$-independent and -dependent bindings of L-[3H]glutamate in rat brain. Life Sci. 1986 Dec 22;39(25):2411-8.

217. Gere-Pászti E, Jakus J. The effect of $\mathrm{N}$-acetylcysteine on amphetamine-mediated dopamine release in rat brain striatal slices by ion-pair reversed-phase high performance liquid chromatography. Biomedical Chromatography. 2009;23(6):658-64.

218. Di Chiara G, Bassareo V. Reward system and addiction: what dopamine does and doesn't do. Current opinion in pharmacology. 2007;7(1):69-76. 
219. Popik P, Wrobel M, Rygula R, Bisaga A, Bespalov A. Effects of memantine, an NMDA receptor antagonist, on place preference conditioned with drug and nondrug reinforcers in mice. Behavioural pharmacology. 2003;14(3):237-44.

220. Thuerauf N, Lunkenheimer J, Lunkenheimer B, Sperling W, Bleich S, Schlabeck M, et al. Memantine fails to facilitate partial cigarette deprivation in smokers--no role of Memantine in the treatment of nicotine dependency? Journal of neural transmission (Vienna, Austria : 1996). 2007 Mar;114(3):351-7.

221. Santa Ana EJ, Rounsaville BJ, Frankforter TL, Nich C, Babuscio T, Poling J, et al. d-Cycloserine Attenuates Reactivity to Smoking Cues in Nicotine Dependent Smokers: A Pilot Investigation. Drug and alcohol dependence. 2009 07/09;104(3):220-7.

222. McClure EA, Gipson CD, Malcolm RJ, Kalivas PW, Gray KM. Potential role of N-acetylcysteine in the management of substance use disorders. CNS drugs. 2014 Feb;28(2):95-106.

223. Kavirajan H. Memantine: a comprehensive review of safety and efficacy. 2009.

224. National Institute for Clinical Excellence. Donepezil, galantamine, rivastigmine and memantine for the treatment of Alzheimer's disease. NICE Technology Appraisal Guidance. 2011;217.

225. Bisaga A, Popik P. In search of a new pharmacological treatment for drug and alcohol addiction: N-methyl-D-aspartate (NMDA) antagonists. Drug and alcohol dependence. 2000;59(1):115.

226. Dani JA. Roles of dopamine signaling in nicotine addiction. Mol Psychiatry. 2003 03/10/print;8(3):255-6.

227. Hurt RD, Ahlskog JE, Croghan GA, Offord KP, Wolter TD, Croghan IT, et al. Carbidopa/levodopa for smoking cessation: a pilot study with negative results. Nicotine $\&$ tobacco research. 2000;2(1):718.

228. Reinholz J, Skopp O, Breitenstein C, Bohr I, Winterhoff H, Knecht S. Compensatory weight gain due to dopaminergic hypofunction: new evidence and own incidental observations. Nutrition \& Metabolism. 2008 12/01

06/03/received

12/01/accepted;5:35-.

229. Jarvik ME, Caskey NH, Wirshing WC, Madsen DC, Iwamoto-Schaap PN, Elins JL. Bromocriptine reduces cigarette smoking. Addiction. 2000;95(8):1173-83.

230. Murphy MFG, Hey K, Johnstone E, Munafo M, Walton R, Willis B, et al. Bromocriptine use is associated with decreased smoking rates. Addiction Biology. 2002;7(3):325-8.

231. Mugnaini M, lavarone L, Cavallini P, Griffante C, Oliosi B, Savoia C, et al. Occupancy of brain dopamine D3 receptors and drug craving: a translational approach. Neuropsychopharmacology : official publication of the American College of Neuropsychopharmacology. 2013 Jan;38(2):302-12.

232. Foulds J, Burke M, Steinberg M, Williams JM, Ziedonis DM. Advances in pharmacotherapy for tobacco dependence. Expert opinion on emerging drugs. 2004 May;9(1):39-53.

233. Conditions NCCfC. Economic modelling-dopamine agonists. 2006.

234. Vengeliene V, Leonardi-Essmann F, Perreau-Lenz S, Gebicke-Haerter P, Drescher K, Gross G, et al. The dopamine D3 receptor plays an essential role in alcohol-seeking and relapse. FASEB J. 2006 Nov;20(13):2223-33.

235. Benowitz NL. Neurobiology of nicotine addiction: implications for smoking cessation treatment. Am J Med. 2008 Apr;121(4 Suppl 1):S3-10.

236. Ray R, Rukstalis M, Jepson C, Strasser A, Patterson F, Lynch K, et al. Effects of atomoxetine on subjective and neurocognitive symptoms of nicotine abstinence. Journal of Psychopharmacology. 2009;23(2):168-76.

237. Garnock-Jones KP, Keating GM. Atomoxetine: a review of its use in attention-deficit hyperactivity disorder in children and adolescents. Paediatr Drugs. 2009;11(3):203-26. 
238. McCarty M, O'Keefe J, DiNicolantonio J. Carvedilol and spirulina may provide important health protection to smokers and other nicotine addicts: a call for pertinent research. Missouri medicine. 2014;112(1):72-5.

239. Klimek V, Zhu M-Y, Dilley G, Konick L, Overholser JC, Meltzer HY, et al. Effects of long-term cigarette smoking on the human locus coeruleus. Archives of general psychiatry. 2001;58(9):821-7.

240. Page ME. The promises and pitfalls of reboxetine. CNS drug reviews. 2003;9(4):327-42.

241. Gehricke J-G, Hong N, Wigal TL, Chan V, Doan A. ADHD medication reduces cotinine levels and withdrawal in smokers with ADHD. Pharmacology Biochemistry and Behavior. 2011;98(3):485-91.

242. Sacco KA, Creeden C, Reutenauer EL, Vessicchio JC, Weinberger AH, George TP. Effects of atomoxetine on cognitive function and cigarette smoking in schizophrenia. Schizophrenia research. 2009;107(2):332-3.

243. Silverstone PH, Dadashova R. Atomoxetine treatment for nicotine withdrawal: a pilot doubleblind, placebo-controlled, fixed-dose study in adult smokers. Annals of General Psychiatry. 2012;11(1):1-11.

244. Sofuoglu M, Mouratidis M, Yoo S, Kosten T. Adrenergic blocker carvedilol attenuates the cardiovascular and aversive effects of nicotine in abstinent smokers. Behav Pharmacol. 2006 Dec;17(8):731-5.

245. Sofuoglu M, Babb D, Hatsukami DK. Labetalol treatment enhances the attenuation of tobacco withdrawal symptoms by nicotine in abstinent smokers. Nicotine $\&$ tobacco research : official journal of the Society for Research on Nicotine and Tobacco. 2003 Dec;5(6):947-53.

246. Bond RA, Glass M. Use of beta-adrenergic inverse agonists for smoking cessation. Google Patents; 2012.

247. Rauhut AS, Mullins SN, Dwoskin LP, Bardo MT. Reboxetine: attenuation of intravenous nicotine self-administration in rats. Journal of Pharmacology and Experimental Therapeutics. 2002;303(2):664-72.

248. Miller DK, Wong EH, Chesnut MD, Dwoskin LP. Reboxetine: functional inhibition of monoamine transporters and nicotinic acetylcholine receptors. J Pharmacol Exp Ther. 2002 Aug;302(2):687-95.

249. Wong E. Method of promoting smoking cessation. Google Patents; 2003.

250. Dadashova R, Silverstone PH. Off-label use of atomoxetine in adults: is it safe? Mental Illness. $201209 / 24$

01/26/received

09/03/revised

09/03/accepted;4(2):e19.

251. Keating GM, Jarvis B. Carvedilol. Drugs. 2003;63(16):1697-741.

252. Ollivier J, Durier P, Bussiere J, Gayet J. Safety and efficacy of once-daily carvedilol vs twicedaily labetalol in mild to moderate hypertension. European journal of clinical pharmacology. 1990;38(2):S164-S6.

253. Mucci M. Reboxetine: a review of antidepressant tolerability. Journal of psychopharmacology (Oxford, England). 1996;11(4 Suppl):S33-7.

254. Dorset NHS. SHARED CARE GUIDELINE FOR THE USE OF ATOMOXETINE IN ADULTS WITH ATTENTION

DEFICIT HYPERACTIVITY DISORDER 2010 [cited; Available from:

http://www.dorsetccg.nhs.uk/Downloads/aboutus/medicinesmanagement/Shared\%20Care\%20Guidelines/Shared\%20care\%20guideline\%20for\%20Atomoxetine\% 20use\%20in\%20adults\%202010.pdf

255. NICE. Cost-effectiveness analysis of interventions to increase uptake and adherence to cardiac rehabilitation programmes 2013 [cited; Available from: 
https://www.nice.org.uk/guidance/CG172/documents/mi-secondary-prevention-update-

appendices-l-n2

256. Lakshmi SP, Reddy AT, Zhang Y, Sciurba FC, Mallampalli RK, Duncan SR, et al. Down-regulated peroxisome proliferator-activated receptor gamma (PPARgamma) in lung epithelial cells promotes a PPARgamma agonist-reversible proinflammatory phenotype in chronic obstructive pulmonary disease (COPD). J Biol Chem. 2014 Mar 7;289(10):6383-93.

257. Adis Insight. OMS 405. 2012 [cited; Available from: http://adisinsight.springer.com/drugs/800035962

258. Ciccocioppo R. Compositions and methods for prophylaxis and treatment of addictions. Google Patents; 2009.

259. Lakshmi SP, Reddy AT, Zhang Y, Sciurba FC, Mallampalli RK, Duncan SR, et al. Down-regulated Peroxisome Proliferator-activated Receptor $\gamma$ (PPAR $\gamma$ ) in Lung Epithelial Cells Promotes a PPAR $\gamma$ Agonist-reversible Proinflammatory Phenotype in Chronic Obstructive Pulmonary Disease (COPD). Journal of Biological Chemistry. 2014 March 7, 2014;289(10):6383-93.

260. Keith RL. Lung Cancer Chemoprevention. Proceedings of the American Thoracic Society. 2012 2012/05/01;9(2):52-6.

261. Levin D, Bell S, Sund R, Hartikainen S, Tuomilehto J, Pukkala E, et al. Pioglitazone and bladder cancer risk: a multipopulation pooled, cumulative exposure analysis. Diabetologia. 2015 2015/03/01;58(3):493-504.

262. Home P. Safety of PPAR Agonists. Diabetes Care. 2011 2011-05-01 00:00:00;34(Supplement 2):S215-S9.

263. Czoski-Murray C, Warren E, Chilcott J, Beverely C, Psyllaki MA, Cowan J. The Clinical and Costeffectiveness of Pioglitazone and Rosiglitazone in the Treatment of type 2 Diabetes.

264. Higgins GA, Sellers EM, Fletcher PJ. From obesity to substance abuse: therapeutic opportunities for 5-HT2C receptor agonists. Trends in Pharmacological Sciences. 2013 10//;34(10):560-70.

265. Bieley HC. Smoking cessation with body weight maintenance and nutritional supplement. Google Patents; 2014.

266. Levin ED, Johnson JE, Slade S, Wells C, Cauley M, Petro A, et al. Lorcaserin, a 5-HT2C agonist, decreases nicotine self-administration in female rats. Journal of Pharmacology and Experimental Therapeutics. 2011;338(3):890-6.

267. Higgins GA, Silenieks LB, Roßmann A, Rizos Z, Noble K, Soko AD, et al. The 5-HT2C receptor agonist lorcaserin reduces nicotine self-administration, discrimination, and reinstatement: relationship to feeding behavior and impulse control. Neuropsychopharmacology : official publication of the American College of Neuropsychopharmacology. 2012;37(5):1177-91.

268. Guy EG, Fisher DC, Higgins GA, Fletcher PJ. Examination of the effects of varenicline, bupropion, lorcaserin, or naltrexone on responding for conditioned reinforcement in nicotine-exposed rats. Behavioural pharmacology. 2014;25(8):775-83.

269. Eisai. News release: LORCASERIN MEETS PRIMARY ENDPOINT AND CONFIRMS PROOF-OFCONCEPT AS POTENTIAL AID FOR SMOKING CESSATION IN INVESTIGATIONAL PHASE II CLINICAL STUDY. 2014 [cited; Available from: http://www.eisai.com/news/news201465.html

270. Shanahan W, Rose JE, Glicklich A, Stubbe S, Halliday D, Zhang J, et al. Lorcaserin For Smoking Cessation Treatment In Cigarette Smokers: A Randomized Phase 2 Trial. American Thoracic Society 2015 International Conference, Denver, CO; 2015; 2015.

271. Hiatt WR, Thomas A, Goldfine AB. What cost weight loss? Circulation. 2012;125(9):1171-7.

272. Finkelstein EA, Kruger E. Meta- and cost-effectiveness analysis of commercial weight loss strategies. Obesity. 2014;22(9):1942-51.

273. Farid P, Abate MA. Buspirone use for smoking cessation. Ann Pharmacother. 1998 Dec;32(12):1362-4.

274. Hilleman DE, Mohiuddin SM, Del Core MG, Sketch MH, Sr. Effect of buspirone on withdrawal symptoms associated with smoking cessation. Arch Intern Med. 1992 Feb;152(2):350-2. 
275. Cropp CD, Gora-Harper ML. Ondansetron use for smoking cessation. Ann Pharmacother. 1995 Oct;29(10):1041-2.

276. Lader M. Assessing the potential for buspirone dependence or abuse and effects of its withdrawal. The American journal of medicine. 1987;82(5):20-6.

277. West R, Hajek P. Randomised controlled trial of ondansetron in smoking cessation. Psychopharmacology. 1996 Jul;126(1):95-6.

278. Newton RE, Marunycz JD, Alderdice MT, Napoliello MJ. Pharmacology, Efficacy, and Safety of a Non-Benzodiazepine AnxiolyticReview of the side-effect profile of buspirone. The American Journal of Medicine. 1986 1986/03/31;80(3):17-21.

279. Constantino-Casas P, Leon-Gonzalez G, Nevarez-Sida A, Valencia-Huarte E, Garcia-Contreras F. [Cost-effectiveness of anxiolytics in anxiety disorders]. Rev Med Inst Mex Seguro Soc. 2010 MayJun;48(3):303-8.

280. Awtry TL, Werling LL. Acute and chronic effects of nicotine on serotonin uptake in prefrontal cortex and hippocampus of rats. Synapse. 2003 Dec 1;50(3):206-11.

281. Brown RA, Niaura R, Lloyd-Richardson EE, Strong DR, Kahler CW, Abrantes AM, et al. Bupropion and cognitive-behavioral treatment for depression in smoking cessation. Nicotine \& tobacco research : official journal of the Society for Research on Nicotine and Tobacco. 2007;9(7):72130.

282. Spring B, Doran N, Pagoto S, McChargue D, Cook JW, Bailey K, et al. Fluoxetine, smoking, and history of major depression: A randomized controlled trial. J Consult Clin Psychol. 2007 Feb;75(1):8594.

283. Minami H, Kahler CW, Bloom EL, Strong DR, Abrantes AM, Zywiak WH, et al. Effects of depression history and sex on the efficacy of sequential versus standard fluoxetine for smoking cessation in elevated depressive symptom smokers. Addictive Disorders \& Their Treatment. 2015;14(1):29-39.

284. Blondal T, Gudmundsson L, Tomasson K, Jonsdottir D, Hilmarsdottir H, Kristjansson F, et al. The effects of fluoxetine combined with nicotine inhalers in smoking cessation-a randomized trial. Addiction. 1999;94(7):1007-15.

285. Covey LS, Glassman AH, Stetner F, Rivelli S, Stage K. A randomized trial of sertraline as a cessation aid for smokers with a history of major depression. The American journal of psychiatry. 2002 Oct;159(10):1731-7.

286. Niaura R, Spring B, Borrelli B, Hedeker D, Goldstein MG, Keuthen N, et al. Multicenter trial of fluoxetine as an adjunct to behavioral smoking cessation treatment. Journal of consulting and clinical psychology. 2002;70(4):887.

287. Demyttenaere K, Jaspers L. Review: Bupropion and SSRI-induced side effects. J Psychopharmacol. 2008 Sep;22(7):792-804.

288. Peveler $R$, Kendrick $T$, Buxton $M$, Longworth $L$, Baldwin $D$, Moore $M$, et al. A randomised controlled trial to compare the cost-effectiveness of tricyclic antidepressants, selective serotonin reuptake inhibitors and lofepramine. Health Technol Assess. 2005 May;9(16):1-134, iii.

289. Byford S, Barrett B, Roberts C, Wilkinson P, Dubicka B, Kelvin RG, et al. Cost-effectiveness of selective serotonin reuptake inhibitors and routine specialist care with and without cognitivebehavioural therapy in adolescents with major depression. The British Journal of Psychiatry. 2007 2007-12-01 00:00:00;191(6):521-7.

290. KENDRICK T, PEVELER R, LONGWORTH L, BALDWIN D, MOORE M, CHATWIN J, et al. Costeffectiveness and cost-utility of tricyclic antidepressants, selective serotonin reuptake inhibitors and lofepramine. Randomised controlled trial. 2006 2006-04-01 00:00:00;188(4):337-45.

291. Lancaster T, Stead LF. Silver acetate for smoking cessation. The Cochrane Library. 2012.

292. Jensen EJ, Schmidt E, Pedersen B, Dahl R. Effect on smoking cessation of silver acetate, nicotine and ordinary chewing gum. Psychopharmacology. 1991;104(4):470-4.

293. Stead LF, Lancaster T. Nicobrevin for smoking cessation. The Cochrane Library. 2006. 
294. MHRA. MHRA UK PUBLIC ASSESSMENT REPORT: Nicobrevin: withdrawn from UK market as risks outweigh benefits 2011 [cited; Available from: http://www.mhra.gov.uk/home/groups/spar/documents/websiteresources/con114612.pdf

295. Wanwimolruk S, Wong S, Coville P, Viriyayudhakorn S, Thitiarchakul S. Cigarette smoking enhances the elimination of quinine. British journal of clinical pharmacology. 1993;36(6):610-4.

296. Ballon JS, Feifel D. A systematic review of modafinil: potential clinical uses and mechanisms of action. Journal of clinical Psychiatry. 2006;67(4):554-66.

297. Gerrard P, Malcolm R. Mechanisms of modafinil: A review of current research. Neuropsychiatric Disease and Treatment. 2007;3(3):349-64.

298. Lerman C, Roth D, Kaufmann V, Audrain J, Hawk L, Liu A, et al. Mediating mechanisms for the impact of bupropion in smoking cessation treatment. Drug and alcohol dependence. 2002;67(2):21923.

299. Schnoll RA, Wileyto EP, Pinto A, Leone F, Gariti P, Siegel S, et al. A placebo-controlled trial of modafinil for nicotine dependence. Drug and alcohol dependence. 2008;98(1):86-93.

300. Sofuoglu M, Waters AJ, Mooney M. Modafinil and nicotine interactions in abstinent smokers. Human psychopharmacology. 2008 Jan;23(1):21-30.

301. Martin CA, Lile J, Guenthner G, Anestis JC, Batten SR, Kelly TH. Behavioral Effects of Modafinil and Nicotine, Alone and in Combination, in Tobacco-Deprived Young Adult Smokers. Journal of clinical psychopharmacology. 2014;34(2):278-81.

302. Schnoll RA, Wileyto EP, Pinto A, Leone F, Gariti P, Siegel S, et al. A placebo-controlled trial of modafinil for nicotine dependence. Drug Alcohol Depend. 2008 Nov 1;98(1-2):86-93.

303. Shearer J, Shanahan M, Darke S, Rodgers C, Van Beek I, McKetin R, et al. A cost-effectiveness analysis of modafinil therapy for psychostimulant dependence. Drug and Alcohol Review. 2010;29(3):235-42.

304. Fowler JS, Logan J, Wang GJ, Volkow ND. Monoamine oxidase and cigarette smoking. Neurotoxicology. 2003 Jan;24(1):75-82.

305. Sarginson JE, Killen JD, Lazzeroni LC, Fortmann SP, Ryan HS, Ameli N, et al. Response to Transdermal Selegiline Smoking Cessation Therapy and Markers in the 15q24 Chromosomal Region. Nicotine \& tobacco research : official journal of the Society for Research on Nicotine and Tobacco. 2015 Sep;17(9):1126-33.

306. Mospan C. Updates in Pharmacotherapy for Smoking Cessation. The Journal for Nurse Practitioners. 2016.

307. George TP, Vessicchio JC, Termine A, Jatlow PI, Kosten TR, O'Malley SS. A preliminary placebocontrolled trial of selegiline hydrochloride for smoking cessation. Biological psychiatry. 2003 1/15/;53(2):136-43.

308. Kahn R, Gorgon L, Jones K, McSherry F, Glover ED, Anthenelli RM, et al. Selegiline Transdermal System (STS) as an Aid for Smoking Cessation. Nicotine \& Tobacco Research. 2012 March 1, 2012;14(3):377-82.

309. Berlin I, Said S, Spreux-Varoquaux O, Launay JM, Olivares R, Millet V, et al. A reversible monoamine oxidase $A$ inhibitor (moclobemide) facilitates smoking cessation and abstinence in heavy, dependent smokers. Clinical pharmacology and therapeutics. 1995 Oct;58(4):444-52.

310. Wimbiscus M, Kostenko O, Malone D. MAO inhibitors: risks, benefits, and lore. Cleve Clin J Med. 2010 Dec;77(12):859-82.

311. David SP, Lancaster T, Stead LF, Evins AE, Cahill K. Opioid antagonists for smoking cessation. The Cochrane Library. 2006.

312. Berrettini W. Opioid neuroscience for addiction medicine: From animal models to FDA approval for alcohol addiction. Progress in Brain Research. 2016;223:253-67.

313. Farley AC, Hajek P, Lycett D, Aveyard P. Interventions for preventing weight gain after smoking cessation. Cochrane Database Syst Rev. 2012;1:CD006219. 
314. Mooney ME, Poling J, Gonzalez G, Gonsai K, Kosten T, Sofuoglu M. Preliminary study of buprenorphine and bupropion for opioid-dependent smokers. American Journal on Addictions. 2008;17(4):287-92.

315. Benyamin R, Trescot AM, Datta S, Buenaventura R, Adlaka R, Sehgal N, et al. Opioid complications and side effects. Pain Physician. 2008 Mar;11(2 Suppl):S105-20.

316. O'Mahony S, Coyle N, Payne R. Current management of opioid-related side effects. Oncology (Williston Park, NY). 2001;15(1):61-73, 7; discussion 7-8, 80-2.

317. De Lima L, Sweeney C, Palmer JL, Bruera E. Potent analgesics are more expensive for patients in developing countries: a comparative study. Journal of Pain \& Palliative Care Pharmacotherapy. 2004;18(1):59-70.

318. Van Gaal LF, Rissanen AM, Scheen AJ, Ziegler O, Rössner S, Group R-ES. Effects of the cannabinoid-1 receptor blocker rimonabant on weight reduction and cardiovascular risk factors in overweight patients: 1-year experience from the RIO-Europe study. The Lancet. 2005;365(9468):138997.

319. Boekholdt SM, Peters RJ. Rimonabant: obituary for a wonder drug. The Lancet. 2010;376(9740):489-90.

320. Cahill K, Ussher Michael H. Cannabinoid type 1 receptor antagonists for smoking cessation. Cochrane Database of Systematic Reviews: John Wiley \& Sons, Ltd; 2011.

321. Steinberg MB, Foulds J. Rimonabant for treating tobacco dependence. Vascular Health and Risk Management. 2007 06/;3(3):307-11.

322. Cahill K, Ussher M. Can cannabinoid type 1 receptor antagonists help smokers to quit, and could they also reduce the amount of weight gained during the quitting process? 2012.

323. Neovius M, Narbro K. Cost-effectiveness of pharmacological anti-obesity treatments: a systematic review. International journal of obesity. 2008;32(12):1752-63.

324. Rosenbaum JF, Fava M, Falk W, Pollack MH, Cohen L, Cohen B, et al. The antidepressant potential of oral S-adenosyl-I-methionine*. Acta Psychiatrica Scandinavica. 1990;81(5):432-6.

325. Butterweck V. Mechanism of action of St John's wort in depression : what is known? CNS drugs. 2003;17(8):539-62.

326. Rapaport MH, Nierenberg AA, Howland R, Dording C, Schettler PJ, Mischoulon D. The treatment of minor depression with St. John's Wort or citalopram: failure to show benefit over placebo. J Psychiatr Res. 2011 Jul;45(7):931-41.

327. Najm WI, Reinsch S, Hoehler F, Tobis JS, Harvey PW. S-adenosyl methionine (SAMe) versus celecoxib for the treatment of osteoarthritis symptoms: a double-blind cross-over trial. [ISRCTN36233495]. BMC Musculoskelet Disord. 2004 Feb 26;5:6.

328. Yang J, He Y, Du YX, Tang LL, Wang GJ, Fawcett JP. Pharmacokinetic properties of Sadenosylmethionine after oral and intravenous administration of its tosylate disulfate salt: a multipledose, open-label, parallel-group study in healthy Chinese volunteers. Clin Ther. 2009 Feb;31(2):31120.

329. Fornal CA, Metzler CW, Mirescu C, Stein SK, Jacobs BL. Effects of Standardized Extracts of St. John's Wort on the Single-Unit Activity of Serotonergic Dorsal Raphe Neurons in Awake Cats: Comparisons with Fluoxetine and Sertraline. Neuropsychopharmacology : official publication of the American College of Neuropsychopharmacology. 2001 12//print;25(6):858-70.

330. Parsons A, Ingram J, Inglis J, Aveyard P, Johnstone E, Brown K, et al. A proof of concept randomised placebo controlled factorial trial to examine the efficacy of St John's wort for smoking cessation and chromium to prevent weight gain on smoking cessation. Drug and alcohol dependence. 2009;102(1):116-22.

331. Sood A, Ebbert JO, Prasad K, Croghan IT, Bauer B, Schroeder DR. A randomized clinical trial of St. John's wort for smoking cessation. The Journal of Alternative and complementary medicine. 2010;16(7):761-7. 
332. Sood A, Prasad K, Croghan IT, Schroeder DR, Ehlers SL, Ebbert JO. S-adenosyl-L-methionine (SAMe) for smoking abstinence: a randomized clinical trial. The Journal of Alternative and Complementary Medicine. 2012;18(9):854-9.

333. Green T, Steingart L, Frisch A, Zarchi O, Weizman A, Gothelf D. The feasibility and safety of Sadenosyl-I-methionine (SAMe) for the treatment of neuropsychiatric symptoms in 22q11.2 deletion syndrome: a double-blind placebo-controlled trial. Journal of Neural Transmission. 2012;119(11):1417-23.

334. Hall SD, Wang Z, Huang SM, Hamman MA, Vasavada N, Adigun AQ, et al. The interaction between St John's wort and an oral contraceptive. Clinical Pharmacology \& Therapeutics. 2003;74(6):525-35.

335. Mischoulon D, Fava M. Role of S-adenosyl-L-methionine in the treatment of depression: a review of the evidence. The American journal of clinical nutrition. 2002;76(5):1158S-61S.

336. Gaster B, Holroyd J. St John's wort for depression: a systematic review. Archives of Internal Medicine. 2000;160(2):152-6.

337. Jacobs MA, Spilken AZ, Norman MM, Wohlberg GW, Knapp PH. Interaction of personality and treatment conditions associated with success in a smoking control program. Psychosomatic Medicine. 1971;33(6):545-56.

338. Edwards NB, Murphy JK, Downs AD, Ackerman BJ, Rosenthal TL. Doxepin as an adjunct to smoking cessation: a double-blind pilot study. The American journal of psychiatry. 1989;146(3):373-6.

339. Pinder RM, Brogden RN, Speight TM, Avery GS. Doxepin up-to-date: a review of its pharmacological properties and therapeutic efficacy with particular reference to depression. Drugs. 1977 Mar;13(3):161-218.

340. Mann A, Catterson A, MacPherson A. Toxicity of imipramine: report on serious side effects and massive overdosage. Canadian Medical Association journal. 1959;81(1):23.

341. Revicki DA, Brown RE, Keller MB, Gonzales J, Culpepper L, Hales RE. Cost-effectiveness of newer antidepressants compared with tricyclic antidepressants in managed care settings. The Journal of clinical psychiatry. 1997;58(2):47-58.

342. Qiumei W, Xiaoxue W. Cost-effectiveness Analysis of Three Therapeutic Regimens for Depression [J]. China Pharmacist. 2005;1:027.

343. Pine-Abata $H$, McNeill A, Murray R, Bitton A, Rigotti N, Raw M. A survey of tobacco dependence treatment services in 121 countries. Addiction. 2013 Aug;108(8):1476-84.

344. Perngparn U, Assanangkornchai S, Pilley C, Aramrattana A. Drug and alcohol services in middle-income countries. Curr Opin Psychiatry. 2008 May;21(3):229-33.

345. Raw M, McNeill A, Murray R. Case studies of tobacco dependence treatment in Brazil, England, India, South Africa and Uruguay. Addiction. 2010;105(10):1721-8.

346. Hao W, CHEN H, SU Z. China: alcohol today. Addiction. 2005;100(6):737-41.

347. West R, May S, West M, Croghan E, McEwen A. Performance of English stop smoking services in first 10 years: analysis of service monitoring data; 2013.

348. Public Health England. Alcohol treatment in England 2013-14. 2014 [cited; Available from: http://www.nta.nhs.uk/uploads/adult-alcohol-statistics-2013-14-commentary.pdf

349. Stead LF, Lancaster T. Combined pharmacotherapy and behavioural interventions for smoking cessation. Cochrane Database Syst Rev. 2012;10:Cd008286.

350. Kotz D, Brown J, West R. 'Real-world' effectiveness of smoking cessation treatments: a population study. Addiction. 2014;109(3):491-9.

351. Kotz D, Fidler J, West R. Factors associated with the use of aids to cessation in English smokers. Addiction. 2009 Aug;104(8):1403-10.

352. West R, Brown J. Theory of addiction: John Wiley \& Sons; 2013.

353. Perkins KA. Improving efficiency of initial tests for efficacy in smoking cessation drug discovery. Expert opinion on drug discovery. 2014;9(11):1259-64. 
354. Kaper J, Wagena E, Willemsen M, Van Schayck C. Reimbursement for smoking cessation treatment may double the abstinence rate: results of a randomized trial. Addiction. 2005;100(7):101220.

355. Bertram MY, Lim SS, Wallace AL, Vos T. Costs and benefits of smoking cessation aids: making a case for public reimbursement of nicotine replacement therapy in Australia. Tobacco control. 2007;16(4):255-60.

356. Beard E, Vangeli E, Michie S, West R. The use of nicotine replacement therapy for smoking reduction and temporary abstinence: an interview study. Nicotine \& Tobacco Research. 2011:ntr297. 357. Foulds J. [Commentary] IMPROVING NRT LABELING AND CORRECTING PUBLIC MISPERCEPTIONS. Addiction. 2008;103(8):1379-80.

358. Brose LS, West R, McDermott MS, Fidler JA, Croghan E, McEwen A. What makes for an effective stop-smoking service? Thorax. 2011;66(10):924-6.

359. Mills EJ, Wu P, Lockhart I, Thorlund K, Puhan M, Ebbert JO. Comparisons of high-dose and combination nicotine replacement therapy, varenicline, and bupropion for smoking cessation: a systematic review and multiple treatment meta-analysis. Annals of medicine. 2012;44(6):588-97.

360. Hajek P, Smith KM, Dhanji A-R, McRobbie H. Is a combination of varenicline and nicotine patch more effective in helping smokers quit than varenicline alone? A randomised controlled trial. BMC medicine. 2013;11(1):140.

361. Ramon JM, Morchon S, Baena A, Masuet-Aumatell C. Combining varenicline and nicotine patches: a randomized controlled trial study in smoking cessation. BMC medicine. 2014;12(1):1.

362. Ebbert JO, Hatsukami DK, Croghan IT, et al. Combination varenicline and bupropion sr for tobacco-dependence treatment in cigarette smokers: A randomized trial. Jama. 2014;311(2):155-63.

363. Benowitz N. Nicotine replacement therapy: what has been accomplished: can we do better? Drugs. 1993;45(2):157-70.

364. Stead Lindsay F, Perera R, Bullen C, Mant D, Hartmann-Boyce J, Cahill K, et al. Nicotine replacement therapy for smoking cessation. Cochrane Database of Systematic Reviews: John Wiley \& Sons, Ltd; 2012.

365. West R, Hajek P, Foulds J, Nilsson F, May S, Meadows A. A comparison of the abuse liability and dependence potential of nicotine patch, gum, spray and inhaler. Psychopharmacology. 2000;149(3):198-202.

366. Greenland S, Satterfield MH, Lanes SF. A meta-analysis to assess the incidence of adverse effects associated with the transdermal nicotine patch. Drug Safety. 1998;18(4):297-308.

367. Joseph AM, Norman SM, Ferry LH, Prochazka AV, Westman EC, Steele BG, et al. The safety of transdermal nicotine as an aid to smoking cessation in patients with cardiac disease. New England Journal of Medicine. 1996;335(24):1792-8.

368. Meine TJ, Patel MR, Washam JB, Pappas PA, Jollis JG. Safety and effectiveness of transdermal nicotine patch in smokers admitted with acute coronary syndromes. The American journal of cardiology. 2005;95(8):976-8.

369. Mills EJ, Wu P, Lockhart I, Wilson K, Ebbert JO. Adverse events associated with nicotine replacement therapy (NRT) for smoking cessation. A systematic review and meta-analysis of one hundred and twenty studies involving 177,390 individuals. Tobacco Induced Diseases. 2010;8(1):1.

370. ASH. Nicotine Replacement Therapy, VAT reduction and sales of NRT. 2007 [cited; Available from: http://www.ash.org.uk/files/documents/ASH 696.pdf

371. Jha P, Peto R, Zatonski W, Boreham J, Jarvis MJ, Lopez AD. Social inequalities in male mortality, and in male mortality from smoking: indirect estimation from national death rates in England and Wales, Poland, and North America. Lancet. 2006 Jul 29;368(9533):367-70.

372. Shahab L, McEwen A. Cost-effectiveness of pharmacotherapy for smoking cessation. NCSCT 2012 [cited; Available from: http://www.ncsct.co.uk/usr/pub/B7 Costeffectiveness pharmacotherapy.pdf

373. ASH. Key dates in the history of anti-tobacco campaigning. [cited; Available from:
[ http://www.ash.org.uk/files/documents/ASH 741.pdf 
374. McRobbie H, Hajek P. Nicotine replacement therapy in patients with cardiovascular disease: guidelines for health professionals. Addiction. 2001;96(11):1547-51.

375. Shiffman S, Di Marino ME, Sweeney CT. Characteristics of selectors of nicotine replacement therapy. Tob Control. 2005 Oct;14(5):346-55.

376. Silla K, Beard E, Shahab L. Characterization of long-term users of nicotine replacement therapy: evidence from a national survey. nicotine \& tobacco research. 2014;16(8):1050-5.

377. Hajek P, West R, Foulds J, Nilsson F, Burrows S, Meadow A. Randomized comparative trial of nicotine polacrilex, a transdermal patch, nasal spray, and an inhaler. Archives of Internal Medicine. 1999;159(17):2033-8.

378. Gonzales D, Bjornson W, Durcan MJ, White JD, Johnston JA, Buist AS, et al. Effects of gender on relapse prevention in smokers treated with bupropion SR. Am J Prev Med. 2002 May;22(4):234-9.

379. Brose LS, West R, McDermott MS, Fidler JA, Croghan E, McEwen A. What makes for an effective stop-smoking service? Thorax. 2011 June 27, 2011.

380. Gilpin EA, Messer K, Pierce JP. Population effectiveness of pharmaceutical aids for smoking cessation: what is associated with increased success? Nicotine \& tobacco research : official journal of the Society for Research on Nicotine and Tobacco. 2006 Oct;8(5):661-9.

381. Perkins KA. Issues in the prevention of weight gain after smoking cessation. Annals of Behavioral Medicine. 1994.

382. Medicines Control Agency. Zyban (bupropion hydrocholride) - safety update. 2002 [cited; Available

http://www.mca.gov.uk/ourwork/monitorsafequalmed/safetymessages/zyban26702.pdf

383. West R, McNeill A, Raw M. Smoking cessation guidelines for health professionals: an update. Thorax. 2000;55(12):987-99.

384. Woolacott N, Jones L, Forbes C, Mather L, Sowden A, Song F, et al. The clinical effectiveness and cost-effectiveness of bupropion and nicotine replacement therapy for smoking cessation: a systematic review and economic evaluation. Health Technology Assessment. 2002;6(16):245pp.

385. Annemans L, Nackaerts K, Bartsch P, Prignot J, Marbaix S. Cost effectiveness of varenicline in Belgium, compared with bupropion, nicotine replacement therapy, brief counselling and unaided smoking cessation. Clinical drug investigation. 2009;29(10):655-65.

386. Shearer J, Shanahan M. Cost effectiveness analysis of smoking cessation interventions. Australian and New Zealand journal of public health. 2006;30(5):428-34.

387. Woolacott NF, Jones L, Forbes CA, Mather LC, Sowden AJ, Song FJ, et al. The clinical effectiveness and cost-effectiveness of bupropion and nicotine replacement therapy for smoking cessation: a systematic review and economic evaluation. Health Technol Assess. 2002;6(16):1-245.

388. Department of Health. Statistics on NHS Stop Smoking services in England. 2006 [cited; Available from: http://www.ic/nhs/pubs/nhsstopsmokingstats2005to2006q4.

389. Richmond R, Zwar N. Review of bupropion for smoking cessation. Drug Alcohol Rev. 2003 Jun;22(2):203-20.

390. Aveyard P, West R. Managing smoking cessation. BMJ. 2007;335(7609):37-41.

391. Hurt RD, Sachs DP, Glover ED, Offord KP, Johnston JA, Dale LC, et al. A comparison of sustained-release bupropion and placebo for smoking cessation. New England Journal of Medicine. 1997;337(17):1195-202.

392. Balmford J, Borland R, Hammond D, Cummings KM. Adherence to and reasons for premature discontinuation from stop-smoking medications: data from the ITC Four-Country Survey. Nicotine \& Tobacco Research. 2011;13(2):94-102.

393. Aubin H-J, Bobak A, Britton JR, Oncken C, Billing CB, Gong J, et al. Varenicline versus transdermal nicotine patch for smoking cessation: results from a randomised open-label trial. Thorax. 2008;63(8):717-24.

394. Tashkin DP, Rennard S, Hays JT, Ma W, Lawrence D, Lee TC. Effects of varenicline on smoking cessation in patients with mild to moderate COPD: a randomized controlled trial. Chest Journal. 2011;139(3):591-9. 
395. Warnier MJ, van Riet EE, Rutten FH, De Bruin ML, Sachs AP. Smoking cessation strategies in patients with chronic obstructive pulmonary disease. European Respiratory Journal. 2012:erj001402012.

396. Kaduri P, Voci S, Zawertailo L, Chaiton M, McKenzie K, Selby P. Real-World Effectiveness of Varenicline Versus Nicotine Replacement Therapy in Patients With and Without Psychiatric Disorders. Journal of addiction medicine. 2015.

397. Langley TE, Huang Y, McNeill A, Coleman T, Szatkowski L, Lewis S. Prescribing of smoking cessation medication in England since the introduction of varenicline. Addiction. 2011;106(7):131924.

398. Ebbert JO, Croghan IT, Sood A, Schroeder DR, Hays JT, Hurt RD. Varenicline and bupropion sustained-release combination therapy for smoking cessation. Nicotine $\&$ tobacco research : official journal of the Society for Research on Nicotine and Tobacco. 2009 Mar;11(3):234-9.

399. Institute for Safe Medication Practices. Strong safety signal seen for new varenicline risks. . 2012 [cited; Available from: www.ismp.org/docs/vareniclinestudy.asp

400. Singh S, Loke YK, Spangler JG, Furberg CD. Risk of serious adverse cardiovascular events associated with varenicline: a systematic review and meta-analysis. Canadian Medical Association Journal. 2011;183(12):1359-66.

401. Harrison-Woolrych M, Maggo S, Tan M, Savage R, Ashton J. Cardiovascular events in patients taking varenicline. Drug safety. 2012;35(1):33-43.

402. Svanström H, Pasternak B, Hviid A. Use of varenicline for smoking cessation and risk of serious cardiovascular events: nationwide cohort study. Bmj. 2012;345.

403. Farrell M, Howes S, Bebbington P, Brugha T, Jenkins R, LEWIS G, et al. Nicotine, alcohol and drug dependence and psychiatric comorbidity Results of a national household survey. The British Journal of Psychiatry. 2001;179(5):432-7.

404. Gunnell D, Irvine D, Wise L, Davies C, Martin R. Varenicline and suicidal behaviour: a cohort study based on data from the General Practice Research Database. Bmj. 2009;339.

405. Thomas KH, Martin RM, Davies NM, Metcalfe C, Windmeijer F, Gunnell D. Smoking cessation treatment and risk of depression, suicide, and self harm in the Clinical Practice Research Datalink: prospective cohort study. Bmj. 2013;347:f5704.

406. Buggy Y, Cornelius V, Fogg C, Kasliwal R, Layton D, Shakir SA. Neuropsychiatric events with varenicline: a modified prescription-event monitoring study in general practice in England. Drug safety. 2013;36(7):521-31.

407. Tonstad S, Davies S, Flammer M, Russ C, Hughes J. Psychiatric adverse events in randomized, double-blind, placebo-controlled clinical trials of varenicline. Drug safety. 2010;33(4):289-301.

408. Kotz D, Viechtbauer W, Simpson C, van Schayck OCP, West R, Sheikh A. Cardiovascular and neuropsychiatric risks of varenicline: a retrospective cohort study. The Lancet Respiratory Medicine.3(10):761-8.

409. Bolin K, Wilson K, Benhaddi H, De Nigris E, Marbaix S, Mork A-C, et al. Cost-effectiveness of varenicline compared with nicotine patches for smoking cessation-results from four European countries. The European Journal of Public Health. 2009;19(6):650-4.

410. Zimovetz EA, Wilson K, Samuel M, Beard SM. A review of cost-effectiveness of varenicline and comparison of cost-effectiveness of treatments for major smoking-related morbidities. Journal of evaluation in clinical practice. 2011;17(2):288-97.

411. Mahmoudi $\mathrm{M}$, Coleman $\mathrm{Cl}$, Sobieraj DM. Systematic review of the cost-effectiveness of varenicline vs. bupropion for smoking cessation. Int J Clin Pract. 2012 Feb;66(2):171-82.

412. Hoogendoorn M, Welsing $P$, Rutten-van Mölken MP. Cost-effectiveness of varenicline compared with bupropion, NRT, and nortriptyline for smoking cessation in the Netherlands. Current medical research and opinion. 2008;24(1):51-61.

413. Liberman JN, Lichtenfeld MJ, Galaznik A, Mastey V, Harnett J, Zou KH, et al. Adherence to varenicline and associated smoking cessation in a community-based patient setting. J Manag Care Pharm. 2013 Mar;19(2):125-31. 
414. Hays JT, Leischow SJ, Lawrence D, Lee TC. Adherence to treatment for tobacco dependence: Association with smoking abstinence and predictors of adherence. Nicotine \& Tobacco Research. 2010:ntq047. 